\title{
Safe Foundation Criteria for Low-Rise Building Structures on Drained Coarse-Grained Steep Soil Slopes in Sri Lanka
}

\author{
P.G.D.S. Jayawickrama, D.M.H.H. Jayawardana, M.N.C. Samarawickrama \\ and D.I. Fernando
}

\begin{abstract}
This study focuses on developing safe foundation criteria models for building structures on drained-granular soil slope terrains. The study initiated with identifying the local slope categorisation criteria exclusively based on the slope angle, ranging from flat to steep slopes. The standard range of drained shear strength parameters of coarse-grained soils in Sri Lankan slope terrains was then determined and estimated to be; angle of internal friction $(\varnothing)=30^{\circ}$ to $38^{\circ}$ and cohesion $(c)=1.0$ to $10 \mathrm{kPa}$. The stability of natural drained coarse-grained slopes has been analysed (through PLAXIS 2D v. 8.2). It revealed that Factor of Safety (FOS) variation against slope angle is non-linear for low and high shear strength slopes and low shear strength-flatter slopes; the FOS reduction rate percentage is low $(8.3 \%)$ in shallow slopes and rapid (34.2\%) for steeper slopes and high shear strength-shallow slopes. It is comparatively low (5.7\%) for flatter slopes and relatively low but rapid (18.7\%) through steeper slopes. As slopes become deep, an inevitable FOS reduction of $23.1 \%$ for low-shear-flatter slopes and $14.7 \%$ for high-shear-flatter slopes is evident. Hence, with the same trend of FOS reduction rate of shallow slopes, authors speculate the reason is due to the approach of critical height phenomena. Upon reaching the critical height, the effects of the overburden on FOS reduction diminishes. Under constant geometrical conditions, a FOS reduction of $0.8 \times(\%$ reduction of $\emptyset$ ) in high cohesive soils to $1.4 \times$ (\% reduction of $\varnothing)$ in low cohesive soils and about $0.2 \times(\%$ reduction of $c$ ) in high friction soils to $0.4 \times$ (\% reduction of $c$ ) in low friction soils is noted. This observation suggests that FOS is highly sensitive to corresponding shear strength parameters, especially the angle of internal friction. For loaded slopes, FOS response for loads in flatter slopes is less compared to steeper slopes, and minimum for strip footings placed at $2.0 \mathrm{~m}$ depth, and maximum for $1.0 \mathrm{~m}$ wide pad footings set at $1.0 \mathrm{~m}$ depth. Similar responses were observed for natural slopes for low and high shear strength loaded slopes in the FOS-Slope Angle-Slope Height relationship. The width and depth effects on FOS for the same foundation types were found to be negligible for most slopes, except for the low shear strength-steep slopes. Though it is costly and practically difficult to implement in residential areas, FOS can be significantly improved (30 to 40\%) with slope modifications and subsequent introduction of tieback type soil anchors. A comprehensive set of foundation criteria models have been proposed for different drained-coarse-grained soil slope scenarios.
\end{abstract}

Keywords: Individual footing; Strip footing; Cohesion; Internal friction angle; Factor of safety PLAXIS; Retaining wall; Shear key; Soil anchoring

\section{Introduction}

Building foundation failures are frequent and proven to be hazardous in elevated areas. Many single and multi-storeyed buildings are constructed on hill slopes due to the development activities and increased hill country population. The building loads are transferred to the hill slope terrain at the foundation level, which may cause hill slope instability. However, most constructions are continued without assessing the risk of instability, and most developers are either not in a financial position or are unaware of the designing of suitable foundations, especially after consulting the required professionals. In Sri Lanka, the National Building Research Organization (NBRO) is the main governing
Eng. P.G.D.S. Jayawickrama, AMIE(SL), MIG(SL), MGS(SL), BTec. Eng. Hons. (OUSL), BSc. Geo. (Peradeniya), Geologist, National Building Research Organization. Email:dsjpinnawella@yahoo.com

(iD) https://orcid.org/0000-0001-8838-8174

Miss. D.M.H.H. Jayawardana, BBA(Peradeniya), BTec. Eng. Hons. (OUSL),

Email:himalidmh@yahoo.com

(iD) https://orcid.org/0000-0001-9473-6155

Eng. M.N.C. Samarawickrama, IntPE (SL), CEng., FIE(SL), MGS (SL), BSc. Eng. Hons. (Moratuwa), MSc. (Peradeniya),

MBA (Moratuwa), Senior Lecturer in Civil Engineering,

Department of Civil Engineering, The Open University of Sri

Lanka, Sri Lanka.

Email:mahesh.samarawickrama@gmail.com

(iD https://orcid.org/0000-0002-5378-764X

Mr. D.I. Fernando, BSc. Eng. Hons. (Moratuwa), MSc. (Moratuwa), Senior Lecturer in Civil Engineering, Department

of Civil Engineering, The Open University of Sri Lanka, Sri Lanka.

Email:indikafernando2001@yahoo.co.uk

(iD) https://orcid.org/0000-0003-0926-8006 
body regulating building construction in these slopes. NBRO has already performed many studies, specifically focusing on landslide mitigation and slope stability, and has introduced some building models that suit slope areas. For simplicity, NBRO [1] proposes a convenient slope categorisation based on the slope face angle for five broad categories of ground slopes based on observations of past landslides. It postulates that the steeper the slope, the higher the tendency for instability and slope instability happening in terrains with slopes steeper than $10^{\circ}-15^{\circ}$.

Type I: Flat Land - slope angle $\lesssim 5^{\circ}$ or ground slope $\lesssim 8 \%$.

Type II: Gentle Slopes - slope angle $\approx 5^{\circ}-11^{\circ}$ or ground slope $\approx 8 \%-20 \%$.

Type III: Moderate Slopes - slope angle $\approx 11^{\circ}$ $17^{\circ}$ or ground slope $\approx 20 \%-30 \%$.

Type IV: Intermediate Slopes - slope angle $\approx$ $17^{\circ}-31^{\circ}$ or ground slope $\approx 30 \%-60 \%$.

Type V: Steep Slopes - slope angle $\gtrsim 31^{\circ}$ or ground slope $\gtrsim 60 \%$ approximately.

Mounia et al. [2] studied the influence on the stability of a slope by the number of floors of a building, and Kourkoulis et al. [3] further investigated the effects of foundation type parametrically (isolated footing vs a rigid raft) on the position of a sliding surface against the stability of the slope.

However, such types of studies are still rare in the local context. Hence, performing similar tasks at this juncture is a national requirement.

Most locally available soil slopes formed by residual soils, derived through in-situ weathering of parent metamorphic rocks [4]. The authors' experience suggests that these residual soils are coarse-grained in most instances, and hence, analysing slopes under drained conditions is reasonable.

This study aimed to achieve the following objectives:

$>$ To present the general geometrical categorisation of local slopes and identify drained shear strength parameters of such slopes with coarse-grained residual.

$>$ To study the natural stability of different slope models of different slope geometries under other drained shear strength parameter conditions.
> To investigate the stability of different slope models under various building load conditions and foundations criteria.

$>$ To propose a group of safe foundation models for low-rise building structures placed on steep drained coarse-grained soil slopes.

\section{Previous Studies}

Kulathilaka and Sujeevan [4] report that in tropical countries like Sri Lanka, excessive rainfall infiltration into a residual soil slope triggers instability.

Das [5] comments that all granular materials (sand, gravel, and rock fill) exhibit similar and fully drained strength behaviour due to their inherent higher permeability levels. These materials are cohesionless, and hence particles do not stick to each other. Thus, in many instances, the failure envelops pass more or less through the origin of the Mohr-Coulomb diagram.

Moreover, Das [5] proposed a range of values for the angle of internal friction for granular soil masses with varying shapes of grain and relative density, given in Table 1 .

Table 1 -Angle of Friction for Sand and Silt [5]

\begin{tabular}{|l|c|}
\hline \multicolumn{1}{|c|}{ Soil Type } & $\emptyset$ (Deg.) \\
\hline Sand: Rounded Grain & $27-30$ \\
\hline Loose & $30-35$ \\
\hline Medium dense & $35-38$ \\
\hline Dense \\
\hline Sand: Angular Grain \\
\hline Loose \\
\hline Medium dense & $30-35$ \\
\hline Dense & $35-40$ \\
\hline Gravel with some sand & $40-45$ \\
\hline
\end{tabular}

Though NBRO [1] considers slope angle to be used as the safety governing criterion, it is only one of many factors contributing to slope instability. Hence, it is unreasonable to recommend general threshold limits to identify stable slopes based solely on the slope angle.

Through laboratory tilting box tests, Chen and Liu [6] have identified that the failure plane pattern in a dry slope mostly tends to be a slip plane parallel to the slope surface. However, they comment that moist slopes fail in a circular pattern, and both failure zones are restricted to shallow depths. 
Mounia et al. [2] describe that the factor of safety (FOS) decreases with reduced embedment of the foundation in slope terrains due to the stress state change in soil, caused by reducing passive pressure towards the slope. They mentioned that FOS is further influenced by the building height and no risk of collapse in slope inclinations between $5^{\circ}$ and $8^{\circ}$ for undrained fine-grained slopes up to threestories.

Sazzad and Haque [7] identified the surcharge effects on the FOS of a slope. They suggest that the proportion of FOS reduction with an increase in surcharge is equal to the proportion of the rise in FOS when the surcharge is reduced and shows a linear relationship between the surcharge and FOS. The reduction of FOS with an increment of slope height is limited to a certain level of height, and further increase results in relatively negligible effects on the FOS [7].

Rabie [8] describes that conventional limit equilibrium methods (LEM) generate more conservative results compared to advanced finite element methods (FEM) since LEM essentially needs to make assumptions on the location and shape of the failure surface. LEMs such as Morgenstern-Prince, Spencer, Bishop, Janbu, and Fellenius divide the soil mass into slices and assume the directions of force acting on each slice. FEM programmes have two analysis approaches employed viz., 'increase the gravity load' model and 'shear strength reduction' model. Powerful FEM based software like PLAXIS uses a shear strength reduction model to calculate the FOS.

FEM based methods produce more reliable results due to their simplicity in generating geometrical elements and the more representative soil mass analysis process, causing each element exposed to the action of the close surrounding elements. Unlike conventional approaches, FEM based programmes like PLAXIS are centred on determining stress fields and corresponding displacements, which facilitate access to the stress-strain behaviour of individual elements. Such detailed analysis can offer detailed operating calculations as curves to evolve displacement-based FOS, considering the deformations and plastic zone localisation [9].

Theoretically, a slope is stable when the FOS> 1 , while the limit equilibrium (collapse) is reached when $\operatorname{FOS}=1$, indicating that the slope is on the verge of instability. If the FOS< 1.0, the slope is unstable. However, the FOS obtained is generally not precise because of the uncertainty of variables, and it falls between 1.25 and 2.00 [2].

Hence, the following uncertainty factors should be considered during slope stability analysis [2] viz.:

$>$ Errors due to the accuracy of the methods of calculating stability.

$>$ Experimental uncertainties of the determination of the mechanical properties in the soil.

\section{Methodology}

The following basic steps, based on the slope categorisation proposed by NBRO, were followed to realise the objectives mentioned above.

$>$ Identify common drained shear strength parameters of coarse-grained residual soils.

$>$ Conduct slope stability analysis for both naturally loaded slopes.

$>$ Development of safe foundation models to be used in the foundation designs.

\subsection{Identify Common Drained Shear Strength Parameters of Coarse-Grained Residual Soils}

Common geotechnical properties of drained shear strength parameters of coarse-grained residual soils in local soil slopes have been obtained from the NBRO databases which possess a wealth of data, especially from the geotechnical investigations conducted in landslide-prone areas of Sri Lanka. The drained shear strength data for coarse-grained soils were obtained through a database of more than 50 site locations, and the outcomes of laboratory direct shear tests specifically carried out for this study. Table 4 presents the results.

\subsection{Conduct Slope Stability Analysis}

Figure 1 describes the sequential procedure of conducting slope stability analysis to determine the FOS levels under different scenarios. The analysis was restricted only to slopes between $30^{\circ}$ to $40^{\circ}$, categorised as "steep slopes" [1], while changing slope heights between $10 \mathrm{~m}$ and $35 \mathrm{~m}$, which is the generally encountered range of slope heights in the present-day construction scenario. 


\subsubsection{Stability Analysis Techniques}

Slope analysis was mainly performed with FEM based PLAXIS 2D v. 8.2 programme. However, the results of the PLAXIS programme were compared and tested for the accuracy level with the results from manual calculations for both natural and loaded (with a distributed surcharge) slopes, adopting the Generalized Slice Method, using Equation 1, as reported by Das [5].

$F O S=\frac{c \sum_{n=1}^{n=p} \Delta L_{n}+\tan \emptyset \sum_{n=1}^{n=p} W_{n} \cos \theta_{n}}{\sum_{n=1}^{n=p} W_{n} \sin \theta_{n}}$

Equation 2 can be used after simplifying Equation 1.

FOS $=\frac{c \sum_{n=1}^{n=p} \Delta L_{n}+\tan \emptyset \sum_{n=1}^{n=p} N}{\sum_{n=1}^{n=p} T}$

Where, $N=W_{n} \cos \theta_{n}$ and $T=W_{n} \sin \theta_{n}$, and other parameters are described in the standard literature.

The Geo-Studio tools of the Slope/W slope stability analysis software, also programmed on the Generalized Slice Method, helped to compare the results further. The manual calculation results are presented in Figure 2 and Table 5 for both natural and loaded slopes, respectively. Figures 3 and Figure 4 present the results derived from Slope/W for natural and loaded slopes, respectively. The FOS levels determined using the PLAXIS programme are depicted in Figure 5 and Figure 6 for natural and loaded slopes, respectively. Table 6 summarises the FOS results generated by three different methods.

\subsubsection{Load Application Representing Building Loads}

During placing foundations, every effort has been made to establish the foundations without disturbing the surface geomorphology, unless in the "last refuge strategy" stage (as discussed below), necessitating slope modification strategies. For the analysis, three (03) column foundations were placed along the gradient of the slope viz., just behind the crest- upper footing (UF), midway - mid footing (MF), and at the bottom and bottom footing (BF). However, the outcomes revealed that the individual behaviour of each type is not significant in most instances and hence only the maximum displacement condition was considered out of three. This fact was not applicable when the slope angle reaches $40^{\circ}$, in which the foundation dimensions for UF were appropriately adjusted to accommodate the slope stability.

Loads have been estimated based on Equation 3 with the assumptions that $2.5 \mathrm{kN} / \mathrm{m}^{2}$ as the imposed load, $24 \mathrm{kN} / \mathrm{m}^{3}$ as the unit weight of concrete, and weight of foundations considered as negligible.

Design Load $=1.4 G_{k}+1.6 Q_{k}$

Where, $G_{k^{-}}$Characteristic dead load and $Q_{k^{-}}$ Characteristic imposed load.

Accordingly, the design column load for a single floor residential building with an RCC roof slab with a column-column distance of 4.0 $\mathrm{m}$ becomes $200 \mathrm{kN}$. This value was multiplied by two and three to determine the design column load for two and three-storied buildings, respectively.

However, when using PLAXIS, the input values of design loads need to be input to the programme in force per unit width $(\mathrm{kN} / \mathrm{m})$. Hence, the real imposed design loads have been divided by $2 \pi$ to arrive at the input value in the form of point loads fed to the PLAXIS programme. Table 2 presents the real and converted imposed loads.

Table 2 - Foundation Imposed Loads

\begin{tabular}{|l|c|c|}
\hline $\begin{array}{l}\text { Type of } \\
\text { Building }\end{array}$ & $\begin{array}{c}\text { Design } \\
\text { Load (kN) }\end{array}$ & $\begin{array}{c}\text { Point Load } \\
(\mathbf{k N})\end{array}$ \\
\hline Single Story & 200 & 32 \\
\hline Two Story & 400 & 64 \\
\hline Three Story & 600 & 96 \\
\hline
\end{tabular}

Apart from the load conversions, FEM based analysis demands soil stiffness constitutive model parameters in modelling stress-related deformations in geotechnical problems. Therefore, Young's modulus $(1.3 \times 104 \mathrm{kN} / \mathrm{m} 2)$, shear modulus $(5.0 \times 103 \mathrm{kN} / \mathrm{m} 2)$, and Poisson's ratio (0.3) were employed as the basic stiffness moduli to model with MohrCoulomb soil model in PLAXIS.

\subsubsection{Stability Analysis Process}

Slope stability analysis was performed under drained conditions in three stages: for natural slopes, loaded slopes (which have reached a FOS of more than 1.5 under natural slope conditions), and loaded slopes after different load modifications.

The FOS behaviour for natural slopes has been analysed under different slope angles $\left(30^{\circ}\right.$ to 
$40^{\circ}$ ), under different drained shear strength parameter combinations $(c, \varnothing)$, and under different slope heights (10 $\mathrm{m}$ to $25 \mathrm{~m}$ ), which cover the range of slope geometries that create enormous stability and practical construction problems, as experienced by the authors. During this analysis, two parameters were varied while keeping the third constant to observe the FOS behaviour.

For example, Table 7 and Figure 7 depict FOS variation for varying slope angles $(\alpha=$ $30^{0}$ to $\left.37^{\circ}\right)$ and heights $(H=10 \mathrm{~m}$ to $25 \mathrm{~m})$ for a slope with $\emptyset=30^{\circ}, c=10 \mathrm{kN} / \mathrm{m}^{2}\left(\varnothing 30^{\circ}-\right.$ c10). Table 8 and Figure 8 present the FOS variation for varying slope heights $(H=15 \mathrm{~m}$ to $35 \mathrm{~m})$ and shear strength parameters for a slope with a slope angle $(\alpha)$ of $33^{\circ}$. Table 9 and Table 10 supported by Figure 9 and Figure 10 present the variation of FOS against different combinations of drained shear strength parameters for slopes with a slope angle $(\alpha)$ of $30^{\circ}$ and $40^{\circ}$, at slope height $(H)$ of $15 \mathrm{~m}$.

In the second stage, the loads have been applied only to the natural slopes, which have reached a FOS greater than 1.50. Table 2 presents foundation loads corresponding to different storied buildings, extending only up to three-stories in this study. After applying the loads, a similar analysis to that of natural slopes was carried out for loaded slopes and for each category of loading conditions, as described below.

Table 3 presents the sequence for load application with different foundation options for different slope scenarios. The analysis starts with applying square pad type foundations having a width of $1.0 \mathrm{~m}$, placed at $1.0 \mathrm{~m}$ depth. The sample set of results are presented in Table 11 and Figure 11 for a slope of $\alpha=30^{\circ}$ with $H=15 \mathrm{~m}$, having soils of $\left(\varnothing 30^{\circ}-c 10\right)$, while foundations of square pad footings (Sqr.) of $1.0 \mathrm{~m} \times 1.0 \mathrm{~m}$, placed at a depth $(D)$ of $1.0 \mathrm{~m}$.

The results presented in Figure 11 were compared using Figures 12, 13, and 14, which were developed based on previous study findings of other territories.

As analysis proceeds, if the FOS is less than 1.5 , then the width has been increased to $1.5 \mathrm{~m}$ and then to $2.0 \mathrm{~m}$, respectively, to check the FOS levels. If FOS is less than $1.50 \mathrm{~m}$, even after expanding the foundation width to $2.0 \mathrm{~m}$, then foundations have been placed at $2.0 \mathrm{~m}$ depth and proceed with the same sequence of analysis until it reaches FOS $>1.50$ at the first instance. Finally, if none of the aforementioned options is viable, then opted for strip footings and proceeded with the same analysis sequence.

A summary of the results corresponding to a slope with $\alpha=30^{\circ}, H=15 \mathrm{~m}$, having (Ø30 c10) is presented in Table 12, while Figure 15 depicts the variation of FOS against foundation type, dimensions, and depth under different load conditions for the particular slope. Moreover, Table 13 and Figure 16 present the FOS variation against the slope angle $(\alpha)$ under various load conditions for slopes with Sqr. foundations $(D-2 / W-1)$ having $(\varnothing 38-c 10), H=$ $15 \mathrm{~m}$.

In instances where FOS is less than 1.50, as revealed in Table 12, the analysis proceeds to the third stage, to resort to "last refuge strategies", when none of the foundation remediations successfully improve the stability. In this stage, the possible last refuge strategies to strengthen the FOS of slopes have been tested through:

1. Modification to slope geometry by introducing cut and fill (slope augmentation) accompanied by retaining walls;

2. Modification to foundations by incorporating shear keys to general foundations; and

3. Further improvement of FOS of retaining walls through tiebacks soil anchors.

In strategy 1, retaining walls have been introduced after applying cuts accompanied by the proposed foundation footing (i.e., the depth and the width of the retaining walls are similar to foundation footings). Modelling the stability of the retaining wall and the slope was carried out with PLAXIS by using the "plate" tool with the "diaphragm wall" material set and adopting appropriate material properties.

Various options have been tested to improve the FOS by placing retaining walls in the same building founding depth with similar foundation dimensions but with different retaining wall heights, $R=1.0 \mathrm{~m}$ and $1.5 \mathrm{~m}$. Table 14 presents the results of the FOS level variation with different building loads, their foundations, and retaining wall criteria for slopes of $H=15 \mathrm{~m}$. 
Shear keys to the general building foundation bases have been introduced as the second strategy. Modelling through PLAXIS was conducted through the "plate" tool with the "footing" material set and adopting appropriate material properties. Table 15 presents the results based on the slope stability analysis for slopes with the building having shear keyed foundations for a slope of $a=30^{\circ}$ with $H=15 \mathrm{~m}\left(\varnothing 30^{\circ}-c 10\right)$, Sqr. $(D-1 / W-1)$, and the corresponding displacement distribution profile is depicted in Figure 17.

The final strategy of the "last refuge strategies" was to introduce a tieback anchor to the retaining walls. The anchor has been modelled using PLAXIS by the "fixed end anchor" tool with an "anchor rod" material set and adopting appropriate material properties. The results of the FOS levels reached for the same slope scenario in strategy two are presented in Table 16, and Figure 18 depicts the corresponding displacement distribution profile.

Table 3 - Load Application Sequence Under Different Slope Scenarios

\begin{tabular}{|l|c|c|}
\hline $\begin{array}{l}\text { Foundation } \\
\text { Type }\end{array}$ & Depth (m) & $\begin{array}{c}\text { Width } \\
\text { (m) }\end{array}$ \\
\hline Pad & 1 & 1 \\
\hline Foundations & 2 & 1 \\
\cline { 2 - 3 } & 2 & 2 \\
\hline \multirow{2}{*}{$\begin{array}{l}\text { Strip } \\
\text { Foundations }\end{array}$} & 1 & 1 \\
\cline { 2 - 3 } & 2 & 1 \\
\hline
\end{tabular}

\subsection{Presentation of the Group of Safe Foundation Models to be Used in the Foundation Designs}

The primary outcomes of the study are presented in a special format, which can be directly adaptable for preliminary design purposes. Figure 19 illustrates a sample set of foundation criteria solutions for a slope with slope angle $(\alpha) 30^{\circ}$ and a slope height $(H)$ of $10 \mathrm{~m}$. As it depicts, the grey-coloured regions pertaining to low $\varnothing$ and $c$ values and hence produce low FOS levels in the natural slopes. The first column at the left bottom corner corresponds to different foundation criteria under normal circumstances, in which FOS is greater than 1.50 after placing the building.
Next to it are the nomenclature corresponding to each foundation criteria ranging from Type I to Type V. The second column from the bottom left corner denotes the third stage, "last refuge strategies", and right next to it are nomenclature corresponding to different foundation criteria accompanied with last refuge strategies, ranging from $\mathbf{A}$ to $\mathbf{E}$. The boxed diagram at the extreme right bottom corner depicts the graphical representation of a corresponding number of floors in a building structure, whilst the mid column on the left side of it describes the key to main abbreviations adopted in presenting these solutions.

If the particular slope has drained shear strength parameters of $\varnothing 38^{\circ}-c 10$, then the designer can choose option Type $\mathbf{I}$, which is individual square pad footings, placed at a depth $(D)$ of $1.0 \mathrm{~m}$ and a width $(W)$ of $1.0 \mathrm{~m}$. This can be adopted for all three types of buildings.

On the other extreme, if the slope is composed of very low drained shear strength parameters, $\varnothing 30^{\circ}-c 5$, then the designer has to resort to option A, which needs the support of a $1.0 \mathrm{~m}$ height $(R)$ retaining wall placed at a depth $(D)$ of $1.0 \mathrm{~m}$ and a width $(W)$ of $2.0 \mathrm{~m}$. This is with individual square pad footings having same foundation dimensions (i.e $2.0 \mathrm{~m} \times 2.0 \mathrm{~m}$ ) and founding depth. Such scenario will satisfy the required FOS levels for all three types of buildings.

However, when the drained shear strength parameters reach $\varnothing 33^{\circ}-c 5$, the designer must seek two different options based on the number of floors in the building. If it is single storied, then it will be sufficient to adopt Type III, which is individual square pad footings, placed at a depth $(D)$ of $2.0 \mathrm{~m}$ with a width $(W)$ of $2.0 \mathrm{~m}$. However, for two- and three-storied buildings, one must adopt Type IV, corresponding to strip foundations, placed at a depth $(D)$ of $1.0 \mathrm{~m}$ and has a width $(W)$ of 1.0 m. Appendix B, from Figure B1 to Figure B14, graphically presents the model solutions for the remaining slope scenarios. 


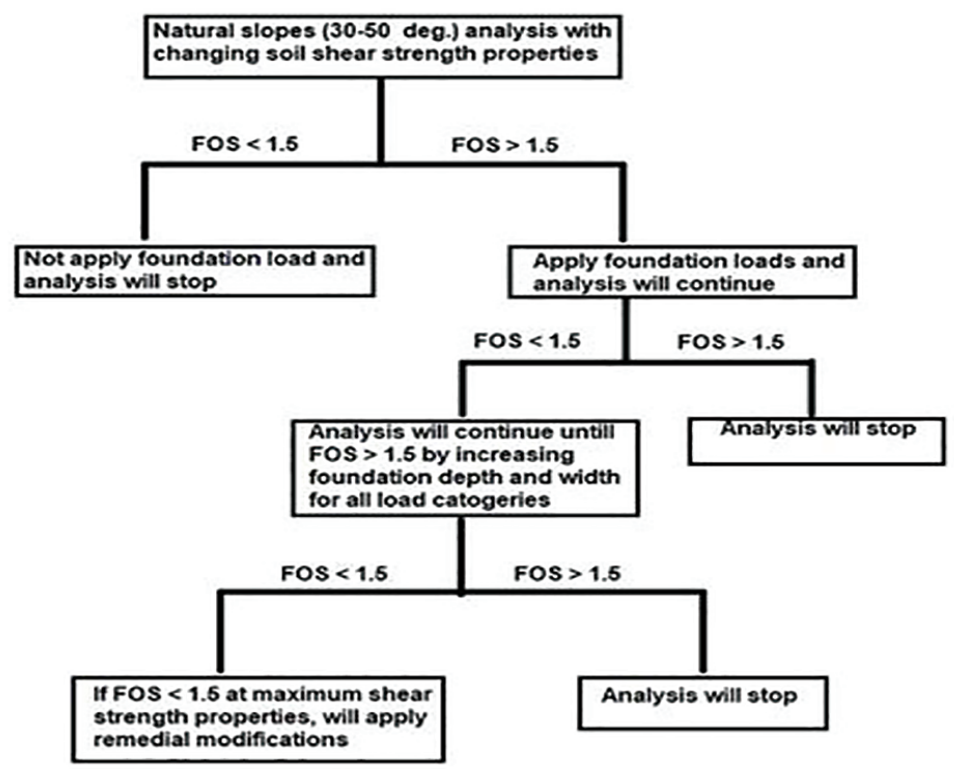

Figure 1 - Slope Stability Analysis process

\section{Analysis and Results}

\subsection{Coarse-Grained Soil Drained Shear Strength Parameters}

Considering the direct shear test data presented in Table 4, it is reasonable to conclude that the drained shear strength parameters of coarse-grained soils in local slopes to be in the range for an angle of internal friction $(\varnothing)$ as $30^{\circ}-38^{\circ}$ and cohesion (c) as 1.0 to $10.0 \mathrm{kPa}$. The dry unit weight $(\gamma)$ of the same types of soils has been estimated to be $18 \mathrm{kN} / \mathrm{m}^{3}$.

\subsection{Factor of Safety Results Using Different Slope Stability Analysis Techniques}

Figures 2 to 6 depict the results for slope stability analysis performed with manual method (Generalized Slice Method), SLOPE/W, and PLAXIS for a slope with $\gamma$ - 18 $\mathrm{kN} / \mathrm{m}^{3}, \varnothing-30^{\circ}$, and $c-5 \mathrm{kN} / \mathrm{m}^{2}$, with a slope angle of $30^{\circ}$ and surcharged with a distributed load of $50 \mathrm{kN} / \mathrm{m}^{2}$.
Table 4 - Direct Shear Test Results for Coarse-Grained Soils Under Drain Condition

\begin{tabular}{|l|c|c|}
\hline \multirow{2}{*}{\multicolumn{1}{|c|}{ Location }} & \multicolumn{2}{|c|}{$\begin{array}{c}\text { Shear } \\
\text { Strength } \\
\text { Parameters }\end{array}$} \\
\cline { 2 - 3 } & $\begin{array}{c}c \\
\mathbf{( k P a )}\end{array}$ & $\left.\emptyset \mathbf{(}^{\circ}\right)$ \\
\hline New hospital, Nuwara Eliya & 10 & 32 \\
\hline Dunkan, Hatton & 10 & 35 \\
\hline Lindula, Nuwara Eliya & 8 & 37 \\
\hline Molagoda, Kegalle & 2 & 38 \\
\hline Dharmaraja, Kandy & 5 & 35 \\
\hline Kuruvita, Ratnapura & 7 & 34 \\
\hline Punchirattota, Matale & 9 & 30 \\
\hline Passara, Badulla & 8 & 33 \\
\hline
\end{tabular}




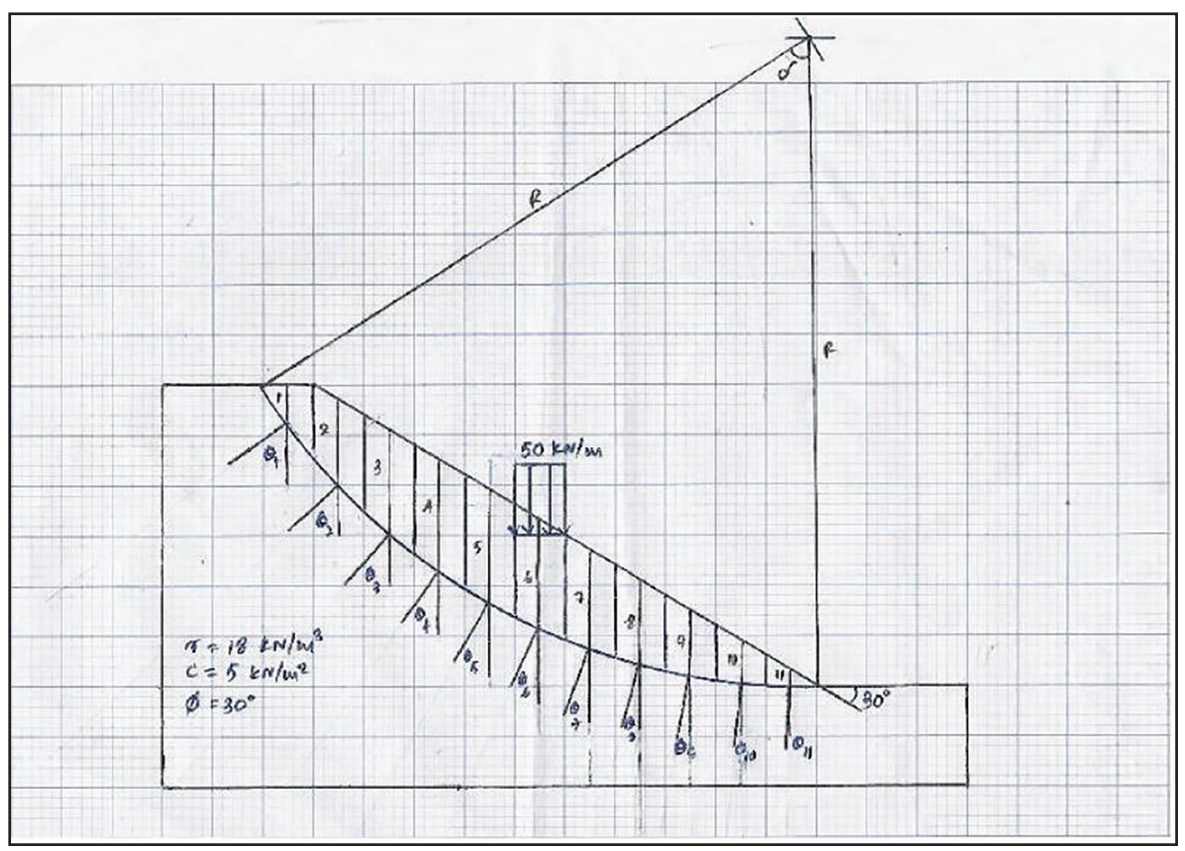

Figure 2 - Graphical Information on Manual Slope Stability Analysis

Table 5 - Manual Slope Stability Analysis Calculation Sheet

\begin{tabular}{|c|c|c|c|c|c|c|c|c|c|c|}
\hline \multirow{2}{*}{$\begin{array}{l}\text { Slice } \\
\text { no. }\end{array}$} & \multirow{2}{*}{$\begin{array}{c}\text { Mid } \\
\text { Height } \\
\text { (m) }\end{array}$} & \multirow{2}{*}{$\begin{array}{c}\text { Width } \\
\text { (m) }\end{array}$} & \multirow{2}{*}{$\begin{array}{l}\text { Volume } \\
\left(\mathrm{m}^{3}\right)\end{array}$} & \multicolumn{2}{|c|}{ Weight (kN) } & \multirow[t]{2}{*}{$\theta$} & \multirow{2}{*}{$\begin{array}{c}N= \\
(W \cos \theta)\end{array}$} & \multirow{2}{*}{$\begin{array}{c}T= \\
(W \sin \theta)\end{array}$} & \multicolumn{2}{|c|}{ With Surcharge } \\
\hline & & & & $\begin{array}{c}\text { Without } \\
\text { Surcharge }\end{array}$ & $\begin{array}{c}\text { With } \\
\text { Surcharge }\end{array}$ & & & & $N_{s}$ & $T_{s}$ \\
\hline 1 & 1.4 & 2 & 2.8 & 50.4 & 201.2 & 54 & 29.62 & 40.77 & 182.35 & 85.03 \\
\hline 2 & 2.4 & 2 & 6.8 & 122.4 & 201.2 & 47 & 83.48 & 84.52 & 182.35 & 85.03 \\
\hline 3 & 4.2 & 2 & 8.4 & 151.2 & 201.2 & 40 & 115.83 & 97.19 & 182.35 & 85.03 \\
\hline 4 & 4.4 & 2 & 8.8 & 158.4 & 201.2 & 35 & 129.75 & 90.85 & 182.35 & 85.03 \\
\hline 5 & 4.4 & 2 & 8.8 & 158.4 & 201.2 & 30 & 137.18 & 79.2 & 182.35 & 85.03 \\
\hline 6 & 4.2 & 2 & 8.4 & 151.2 & 201.2 & 25 & 137.03 & 63.4 & 182.35 & 85.03 \\
\hline 7 & 3.8 & 2 & 7.6 & 136.8 & 201.2 & 20 & 128.55 & 46.79 & 182.35 & 85.03 \\
\hline 8 & 3.2 & 2 & 6.4 & 115.2 & 201.2 & 15 & 111.27 & 29.82 & 182.35 & 85.03 \\
\hline 9 & 2.6 & 2 & 5.2 & 93.6 & 201.2 & 10 & 92.18 & 16.25 & 182.35 & 85.03 \\
\hline 10 & 1.6 & 2 & 3.2 & 57.6 & 201.2 & 6 & 57.28 & 10.02 & 182.35 & 85.03 \\
\hline 11 & 0.6 & 2 & 1.2 & 21.6 & 201.2 & 2 & 21.58 & 0.75 & 182.35 & 85.03 \\
\hline \multicolumn{2}{|c|}{ Total } & 22 & & & & & 1043.75 & 561.06 & 1084.07 & 582.14 \\
\hline
\end{tabular}

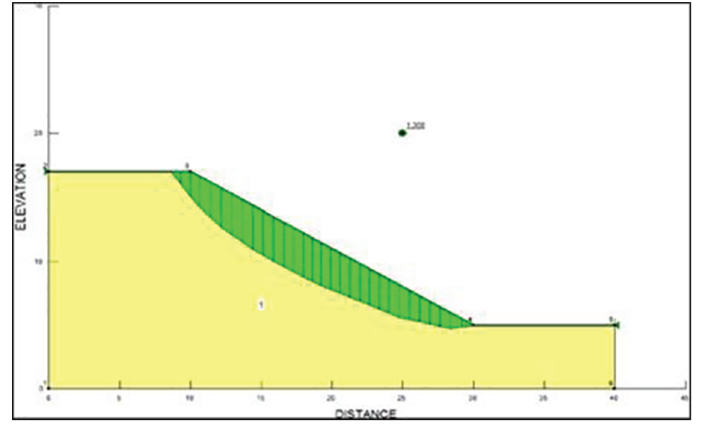

Figure 3 - Natural Slope Analysed With SLOPE/W- FOS-1.366

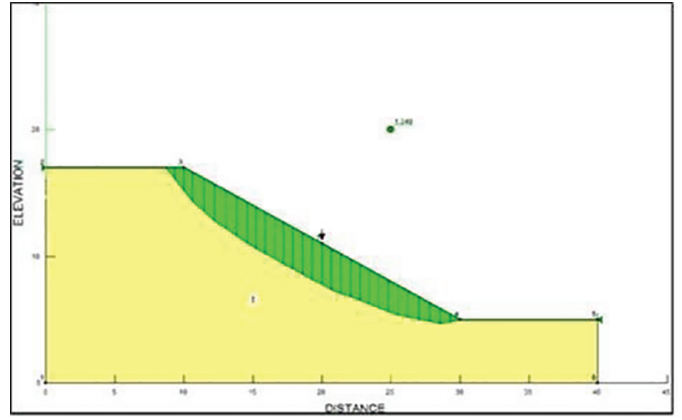

Figure 4 - Surcharged Slope Analysed with SLOPE/W- FOS-1.343 


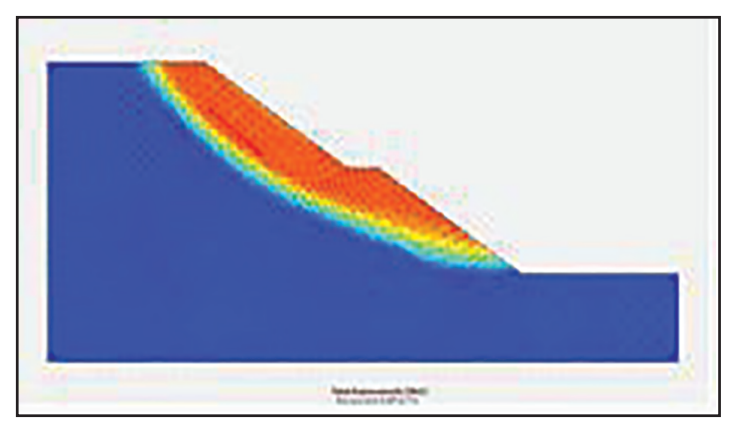

Figure 5 - Natural Slope Analysed with PLAXIS- FOS-1.3662

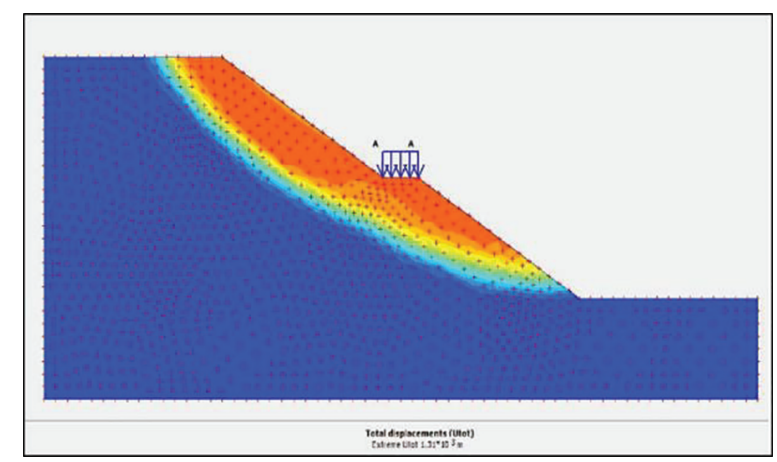

Figure 6 - Surcharged Slope Analysed with PLAXIS- FOS-1.3540

Table 6 shows that a significant difference in results generated among the three approaches is not evident. Hence PLAXIS was used to proceed with the study while considering the reliability factors, as discussed under Section 2.

Table 6 - Comparisons of FOS Calculated with Different Analysis Methods

\begin{tabular}{|l|c|c|c|}
\hline \multirow{2}{*}{$\begin{array}{l}\text { Slope } \\
\text { Load } \\
\text { Condition }\end{array}$} & \multicolumn{3}{|c|}{ Analysis method } \\
\cline { 2 - 4 } & Manual & Slope/W & PLAXIS \\
\hline $\begin{array}{l}\text { FOS } \\
\text { without } \\
\text { surcharge }\end{array}$ & 1.313 & 1.366 & 1.366 \\
\hline $\begin{array}{l}\text { FOS with } \\
\text { surcharge }\end{array}$ & 1.310 & 1.343 & 1.354 \\
\hline
\end{tabular}

Table 7 - FOS Variation Against Slope Angles (a) and heights, $H$ for soil of ( $\varnothing 30^{\circ}-$ c10)

\begin{tabular}{|c|c|c|c|c|}
\hline \multirow{2}{*}{$\begin{array}{l}\text { Slope } \\
\text { Angle }(\boldsymbol{\alpha})\end{array}$} & \multicolumn{4}{|c|}{ Slope Height, $\boldsymbol{H}(\mathbf{m})$} \\
\cline { 2 - 5 } & $\mathbf{1 0}$ & $\mathbf{1 5}$ & $\mathbf{2 0}$ & $\mathbf{2 5}$ \\
\hline $\mathbf{3 0 ^ { 0 }}$ & 1.84 & 1.55 & 1.51 & 1.44 \\
\hline $\mathbf{3 3}^{0}$ & 1.76 & 1.44 & 1.39 & 1.31 \\
\hline $\mathbf{3 5}^{0}$ & 1.72 & 1.34 & 1.29 & 1.22 \\
\hline $\mathbf{3 7 0}$ & 1.66 & 1.27 & 1.24 & 1.13 \\
\hline
\end{tabular}

4.3 Effects of Slope Angle, Height, and Drained Shear Strength Parameters on FOS of a Natural Slope

As depicted in Table 7, FOS has been decreased in the slope of $\left(\varnothing 30^{\circ}-c 10\right)$ by $9.8 \%$ to $21.5 \%$ as the slope angle increases from $30^{\circ}$ $37^{0}$ for the same slope height, and the intensity increases with the increase in the slope height. Meanwhile, it decreases by as much as $21.7 \%$ to $31.9 \%$ as the slope height increases from $10 \mathrm{~m}-25 \mathrm{~m}$ for the same slope angle, and the intensity increases with an increase in the slope angle. It is evident from Figure 7 that a soil slope with $\varnothing 30^{\circ}-c 10$ will not sustain its stability as the slope angle approaches $40^{\circ}$ for any of the slope heights greater than $10 \mathrm{~m}$.

As per Table 8 and Figure 8 , for a slope of $a=33^{\circ}$, a reduction of FOS is in the range of $17.5 \%$ to $20.5 \%$, when the slope height increases from $15 \mathrm{~m}$ to $35 \mathrm{~m}$ under different drained shear strength parameter combinations. In contrast, the decrease in FOS of only about $13 \%$ to $14 \%$ is attributed to the reduction in shear strength parameter combinations. The impact of reduction on FOS attributed to the angle of internal friction is higher than that of cohesion as about 13.1\% reduction in $\varnothing$ has caused to reduce around $13.6 \%$ reduction in FOS, whilst only approximately $10.5 \%$ reduction in FOS is attributed to as much as $50 \%$ reduction in $c$. Similar to the slope angle effect, none of the considered shear strength parameter combinations have supported the safe sustenance of a slope of $a=33^{\circ}$, as the slope height approaches $40 \mathrm{~m}$.

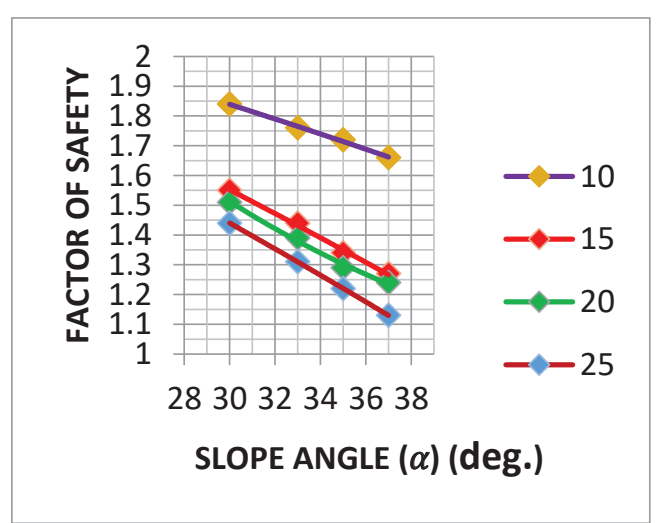

Figure 7 - FOS Vs. Slope Angle (a) and Slope Height, $H$ 
Table 8 - FOS Variation Against Slope Heights, $H$, for $a=30^{\circ}$ Slope

\begin{tabular}{|c|c|c|c|c|c|}
\hline \multirow{2}{*}{$\begin{array}{c}\text { Slope } \\
\text { Height, } H \\
(\mathbf{m})\end{array}$} & \multicolumn{5}{|c|}{ Angle of Internal Friction (Ø) and Cohesion $(c)$} \\
\cline { 2 - 6 } & $\varnothing 38-c \mathbf{1 0}$ & $\varnothing 38-c 7$ & $\varnothing 38-c 5$ & $\varnothing 35-c 10$ & $\varnothing 33-c 10$ \\
\hline 15 & 1.85 & 1.71 & 1.63 & 1.70 & 1.61 \\
\hline 20 & 1.64 & 1.53 & 1.47 & 1.49 & 1.42 \\
\hline 25 & 1.55 & 1.46 & 1.41 & 1.43 & 1.36 \\
\hline 30 & 1.53 & 1.44 & 1.37 & 1.39 & 1.33 \\
\hline 35 & 1.49 & 1.41 & 1.34 & 1.36 & 1.28 \\
\hline
\end{tabular}

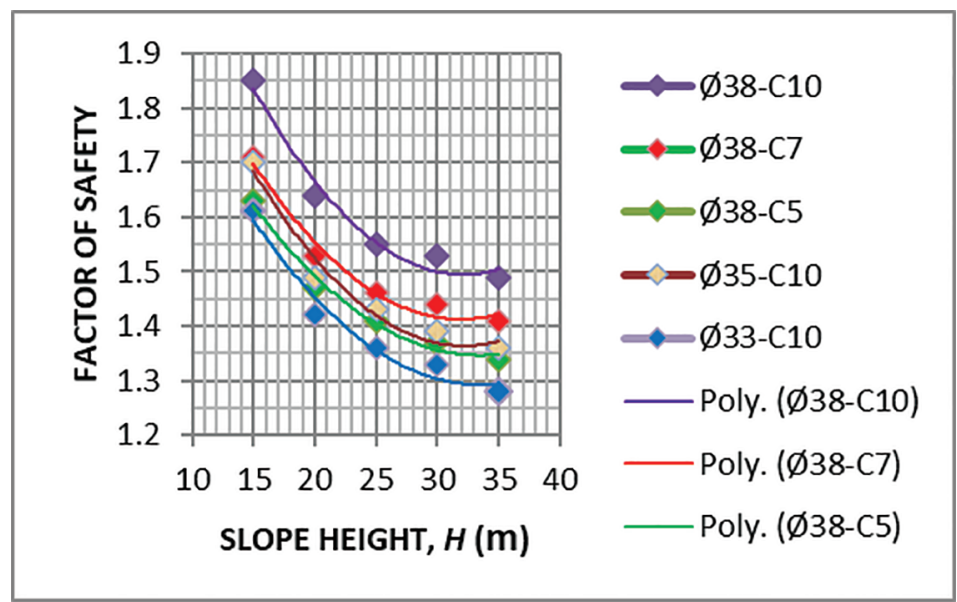

Figure 8 - FOS Vs. Slope Height for $33^{\circ}$ Slope

Table 9 - FOS Variation Against Shear Strength Parameters for a Slope of $a=30^{\circ}$ and $H=15 \mathrm{~m}$ for Different Combinations of $c$ and $\varnothing$

\begin{tabular}{|c|c|c|c|c|}
\hline \multirow{2}{*}{$\begin{array}{c}\text { Cohesion } \\
(\mathbf{k P a})\end{array}$} & \multicolumn{4}{|c|}{ Friction Angles( $\boldsymbol{(}^{\mathbf{0}}$} \\
\hline & $\boldsymbol{\varnothing - 3 0}$ & $\boldsymbol{\varnothing - 3 3}$ & $\boldsymbol{\varnothing - 3 5}$ & $\boldsymbol{\varnothing - 3 8}$ \\
\hline 1 & & & & 1.42 \\
\hline 3 & & & & 1.56 \\
\hline 5 & & & & 1.70 \\
\hline 7 & & & & 1.81 \\
\hline 10 & & & & 1.94 \\
\hline
\end{tabular}

Table 10 - FOS Variation Against Shear Strength Parameters for a Slope of $a=40^{\circ}$ and $H=15 \mathrm{~m}$ for Different combinations of $c$ and $\varnothing$

\begin{tabular}{|c|c|c|c|c|}
\hline \multirow{2}{*}{$\begin{array}{c}\text { Cohesion } \\
(\mathbf{k P a})\end{array}$} & \multicolumn{4}{|c|}{ Friction Angles $\left(\boldsymbol{(}^{\mathbf{0}}\right)$} \\
\cline { 2 - 5 } & $\boldsymbol{\varnothing - 3 0}$ & $\boldsymbol{\varnothing - 3 3}$ & $\boldsymbol{\varnothing - 3 5}$ & $\boldsymbol{\varnothing - 3 8}$ \\
\hline 1 & 0.73 & 0.83 & 0.89 & 0.98 \\
\hline 3 & 0.82 & 0.94 & 1.00 & 1.08 \\
\hline 5 & 0.90 & 0.98 & 1.09 & 1.18 \\
\hline 7 & 1.00 & 1.09 & 1.17 & 1.25 \\
\hline 10 & 1.12 & 1.21 & 1.28 & 1.35 \\
\hline
\end{tabular}

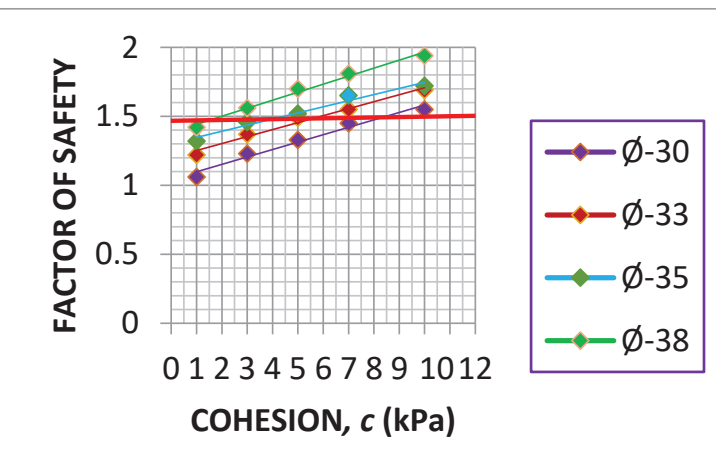

Figure 9 - FOS Vs. Cohesion and Angle of Internal Friction for $a=30^{\circ}$ and $H=15 \mathrm{~m}$ Slope

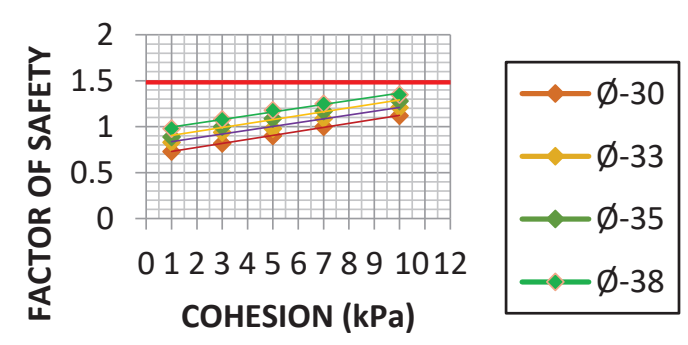

Figure 10 - FOS Vs. Cohesion and Angle of Internal Friction for $a=40^{\circ}$ and $H=15 \mathrm{~m}$ Slope 
Shear strength parameters from the combined effects and the slope angle on the slope stability are elaborated and presented for a slope height of $15 \mathrm{~m}$ in Table 9, Table 10, Figure 9, and Figure 10. Similar to previous results, $\varnothing$ has a greater impact on the FOS (about 0.8 to 1.2 times the reduction of $\varnothing$ ) compared to the influence by $c$ (only about 0.3 to 0.4 times the reduction of $c$ ). As the aforementioned Tables and Figures depict, the FOS has been reduced by around $25.5 \%$ to $32.5 \%$ as slope angle increases from $30^{\circ}$ to $40^{\circ}$ under same shear strength parameter conditions, the least for high cohesive and moderate friction soils. Moreover, even with the highest cohesion and friction soil, a slope is found to be unstable as it reaches a slope angle of $40^{\circ}$, while the majority of the high cohesive low friction soils exist above the stability threshold limit when the slope angle reaches $30^{\circ}$. For non-cohesive soils, again, the slope of even $30^{\circ}$ is found to be unstable.

When considering the behaviour of FOS in Figure 8, similar behaviour has been reported by Sazzad and Haque [7], as shown in Figure 11, in which they mention that FOS decreases significantly down to a certain slope height, beyond which it has an insignificant effect on the FOS. This fact is found applicable to this study result when the behaviour of the latter parts of the curves in Figure 8 are carefully observed.

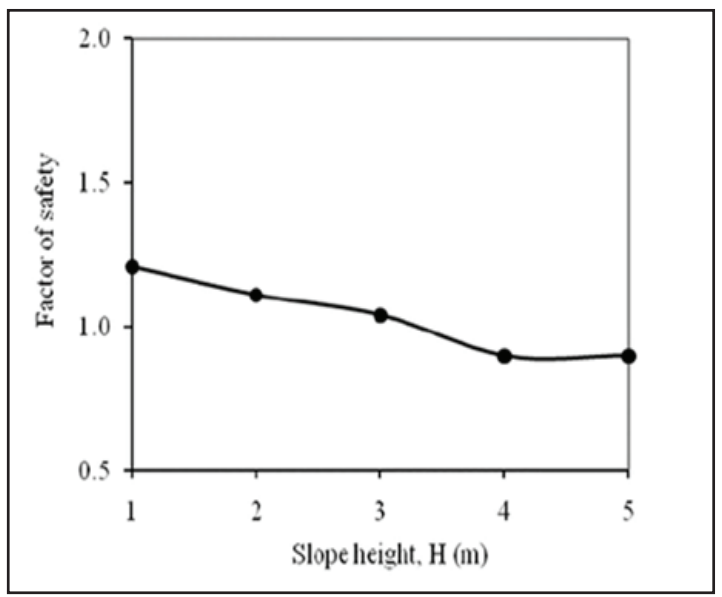

Figure 11 - Effect of Slope Height on the FOS [7]

\subsection{Effects of Loads and Foundation Parameters on FOS}

Table 11 and Figure 12 present FOS variation against building loads corresponding to the number of stories, where $1.0 \mathrm{~m}$ square footing foundations placed at $1.0 \mathrm{~m}$ depth in a slope of $a=30^{\circ}$ with $H=15 \mathrm{~m}$ and $\left(\varnothing 30^{\circ}-c 10\right)$. It is evident that the FOS has been reduced by around $3.2 \%, 6.5 \%$, and $11.6 \%$ for single, two and three-storied buildings, respectively.

Table 11 - FOS Variation with Building Loads for a Slope $a=30^{\circ}$ with $H=15 \mathrm{~m}$ $\left(\varnothing 30^{\circ}-c 10\right)$, Sqr. $(D-1 / W-1)$

\begin{tabular}{|c|c|}
\hline Number of floors & FOS \\
\hline Natural & 1.55 \\
\hline Single & 1.50 \\
\hline Two & 1.45 \\
\hline Three & 1.37 \\
\hline
\end{tabular}

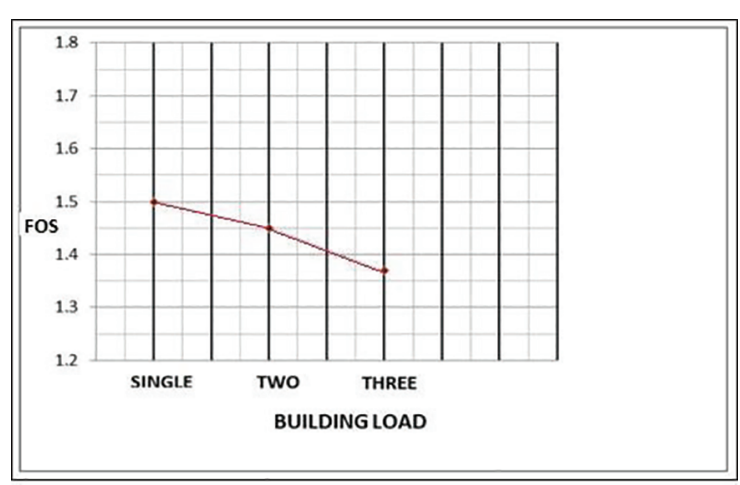

Figure 12 - FOS Values vs. Building Loads for a Slope $a=30^{\circ}$ with $H=15 \mathrm{~m}\left(\varnothing 30^{\circ}-c 10\right)$, Sqr. $(D-1 / W-1)$

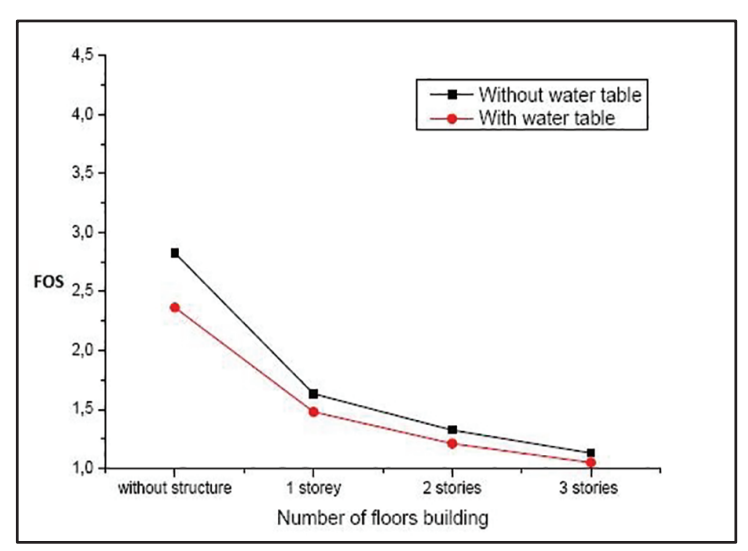

Figure 13 - FOS Values vs. Building Loads According to [2]

As Mounia et al. [2] report, in Figure 13, a similar trend is observed for the slope stability case described in Figure 12.

As per Table 12 and Figure 14, the type of foundation, its depth, and dimensions have a significant bearing on the FOS of a slope. For example, for single-storied buildings, FOS of 1.50 is reached with individual footings with $1.0 \mathrm{~m}$ width, placed at $1.0 \mathrm{~m}$ depth; a better FOS could be achieved with a strip foundation placed at $1.0 \mathrm{~m}$ depth. 
Table 12 - FOS Variation for a Loaded Slope of $a=30^{\circ}, H=15 \mathrm{~m}$ with $(\varnothing 30-c 10)$

\begin{tabular}{|l|c|c|c|}
\hline \multirow{2}{*}{$\begin{array}{l}\text { Foundation } \\
\text { Type }\end{array}$} & \multicolumn{3}{|c|}{ Number of floors } \\
\cline { 2 - 4 } & Single & Two & Three \\
\hline Sqr. $(D-1 / W-1)^{*}$ & 1.50 & 1.45 & 1.37 \\
\hline Sqr. $(D-2 / W-1)$ & 1.52 & 1.48 & 1.42 \\
\hline Sqr. $(D-2 / W-2)$ & 1.51 & 1.47 & 1.42 \\
\hline Strip $(D-1) * *$ & 1.51 & 1.46 & 1.41 \\
\hline Strip(D-2) & 1.55 & 1.51 & 1.47 \\
\hline
\end{tabular}

Table 13 and Figure 15 reveal that even the most stable slopes (out of the concerned slopes) become unstable for some loading and foundation criteria.

Sazzad and Haque [7] have presented similar observations to that of Figure 15, as reported in Figure 16.

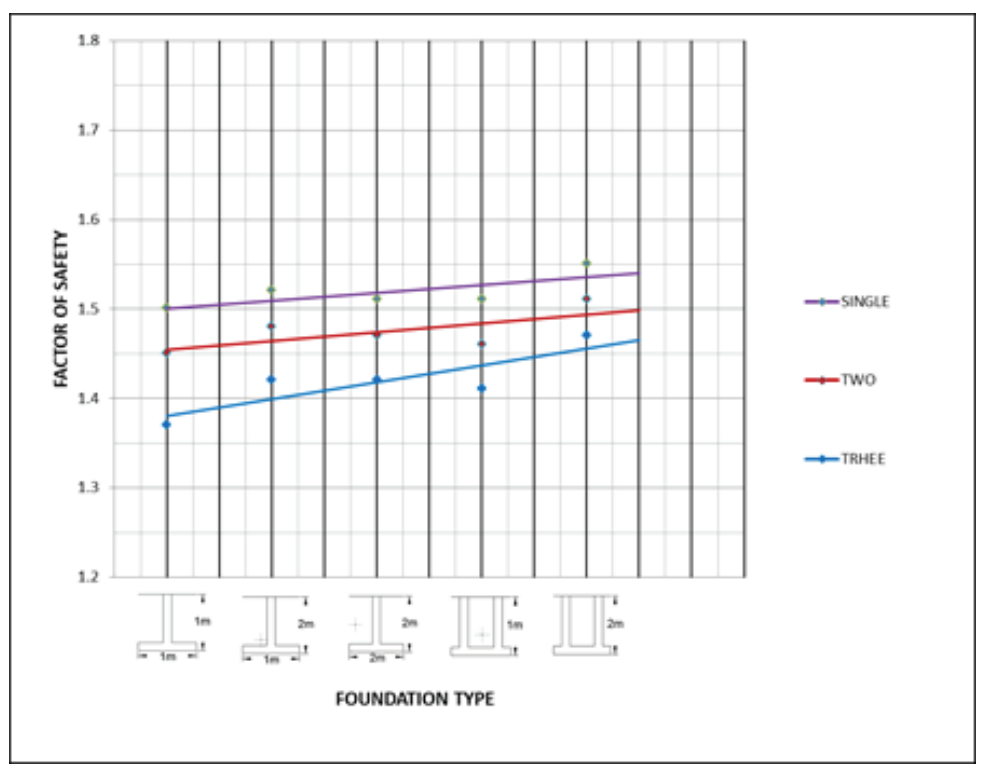

Figure 14 - FOS vs. Foundation Type, Dimensions, and Depth Under Different Load Conditions for a Slope of $\alpha=30^{\circ}, H=15 \mathrm{~m}$ with $(\varnothing 30-c 10)$

Table 13 - FOS Variation with Slope Angle $(\alpha)$ and Building Loads with Foundations of Sqr. $(D-2 / W-1)$ for slopes of $(\varnothing 38-c 10), H=15$ m

\begin{tabular}{|c|c|c|c|c|}
\hline $\begin{array}{c}\text { Slope } \\
\text { Angle } \\
(\boldsymbol{\alpha})\end{array}$ & $\begin{array}{c}\text { Natural } \\
\text { Slope }\end{array}$ & \multicolumn{3}{|c|}{ Number of Floors } \\
\hline $30^{0}$ & 1.94 & 1.89 & 1.81 & 1.70 \\
\cline { 3 - 5 } & & One & Two & Three \\
\hline $33^{0}$ & 1.78 & 1.75 & 1.65 & 1.58 \\
\hline $35^{0}$ & 1.66 & 1.63 & 1.54 & 1.48 \\
\hline $37^{0}$ & 1.57 & 1.52 & 1.47 & 1.43 \\
\hline
\end{tabular}

* Individual footing-placed at $1.0 \mathrm{~m}$ depth and having $1.0 \mathrm{~m}$ width

** Strip foundation-placed at $1.0 \mathrm{~m}$ depth Key: SqrSquare individual pad footing, Strip-strip footing, $D$-founding depth in $\mathrm{m}, W$-foundation width in $\mathrm{m}$.

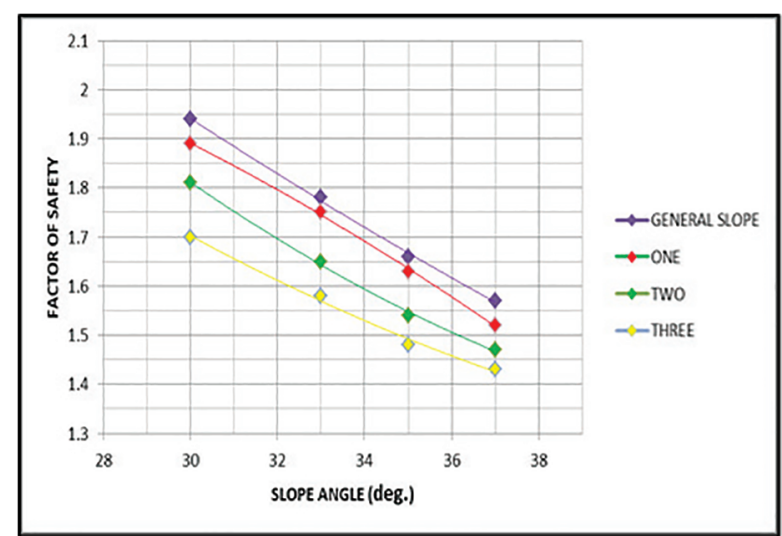

Figure 15 - FOS Against Slope Angle $(\alpha)$ and Building Loads with Foundations Sqr. ( $D$ 2/W-1) for Slopes of $(\varnothing 38-c 10)$ and $H=15 \mathrm{~m}$ 


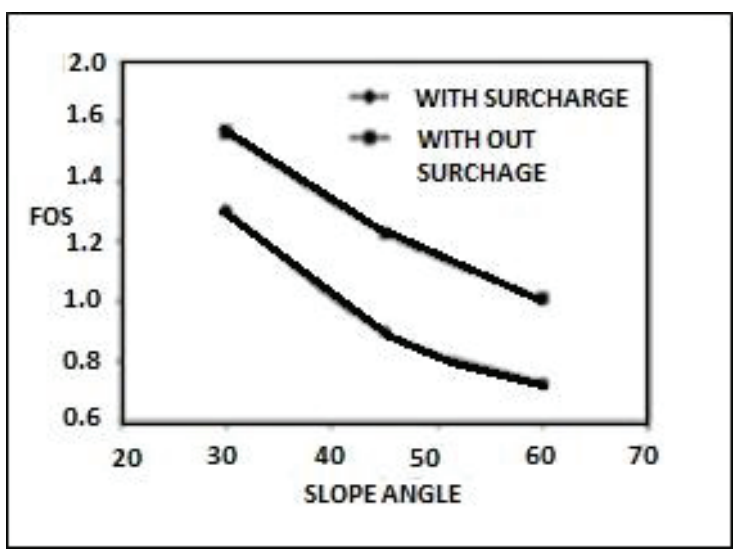

Figure 16 - Effect of Slope Angle on the FOS [7]

\subsection{Slope and Foundation Augmentations to Improve the FOS}

\subsubsection{Slope Augmentation Accompanied with Retaining Walls}

Based on the results under section 4.4, the slopes that reached FOS $<1.5$ have been augmented with a cut, and simultaneously, retaining walls have been introduced. Initially, this has been tested for individual footings and proved successful for most cases for three levels of building loads, as shown in Table 14 .

Table 14 - FOS Variation for Modified Slopes of $H=15 \mathrm{~m}$ with the Introduction of Retaining Walls

\begin{tabular}{|c|c|c|c|c|c|}
\hline \multirow{2}{*}{$\begin{array}{l}\text { Slope } \\
\text { Angle } \\
\text { (a) }\end{array}$} & \multirow[t]{2}{*}{$\varnothing^{0-} c(\mathbf{k P a})$} & \multirow[t]{2}{*}{$\begin{array}{l}\text { Retaining Wall } \\
\text { Details }\end{array}$} & \multicolumn{3}{|c|}{$\begin{array}{l}\text { FOS for Number of } \\
\text { Floors }\end{array}$} \\
\hline & & & 1 & 2 & 3 \\
\hline $30^{\circ}$ & $30-10$ & $1 D-2 W-1 R W$ & - & 1.504 & 1.459 \\
\hline $30^{\circ}$ & $30-10$ & $2 D-2 W-1 R W$ & - & 1.533 & 1.509 \\
\hline $30^{\circ}$ & $33-7$ & $1 D-2 W-1 R W$ & - & 1.520 & 1.478 \\
\hline $30^{\circ}$ & $33-7$ & $2 D-2 W-1 R W$ & - & 1.533 & 1.509 \\
\hline $30^{\circ}$ & $35-5$ & $2 D-2 W-1 R W$ & - & - & 1.523 \\
\hline $30^{\circ}$ & $38-3$ & $2 D-2 W-1 R W$ & - & - & 1.591 \\
\hline $33^{0}$ & $33-10$ & $1 D-2 W-1 R W$ & - & 1.501 & 1.445 \\
\hline $33^{\circ}$ & $33-10$ & $1 D-2 W-1.5 R W$ & - & 1.553 & 1.512 \\
\hline $33^{0}$ & $38-5$ & $2 D-2 W-1 R W$ & - & 1.509 & 1.480 \\
\hline $33^{0}$ & $38-5$ & $2 D-2 W-1.5 R W$ & - & 1.565 & 1.538 \\
\hline $35^{0}$ & $35-10$ & $2 D-2 W-1.5 R W$ & 1.515 & 1.491 & 1.467 \\
\hline $35^{0}$ & $35-10$ & $2 D-2 W-2 R W$ & 1.550 & 1.510 & 1.479 \\
\hline $35^{0}$ & $35-10$ & $\begin{array}{l}2 D-2 W-3 W \\
(U F)-2 R W\end{array}$ & 1.567 & 1.535 & 1.502 \\
\hline $37^{0}$ & $38-10$ & $2 D-2 W-1 R W$ & - & 1.542 & 1.509 \\
\hline
\end{tabular}

Key: $D$-Founding depth in $\mathrm{m}, W$-Foundation width in $\mathrm{m}, R W$ - Height of the retaining wall in $\mathrm{m}, W(U F)$ Width of upper pad footing in $\mathrm{m}$
4.5.2 Introduction of Shear Keys to Foundation

Similar to 4.5.1, unstable slopes with individual footings in section 4.4 have been tested for an introduced shear key to the base of the individual footings. However, as depicted in Table 15, the FOS improvement is insignificant.

Table 15 - FOS Levels After Applying Shear Keys to the Foundation Base for a Slope $a=30^{\circ}$ with $H=15 \mathrm{~m}\left(\varnothing 30^{\circ}-c 10\right)$, Sqr. (D-1/W-1)

\begin{tabular}{|l|l|}
\hline \multicolumn{1}{|c|}{ Load Conditions } & FOS \\
\hline Natural slope & 1.566 \\
\hline Single story & 1.507 \\
\hline Two-story & 1.475 \\
\hline Three-story & 1.435 \\
\hline
\end{tabular}

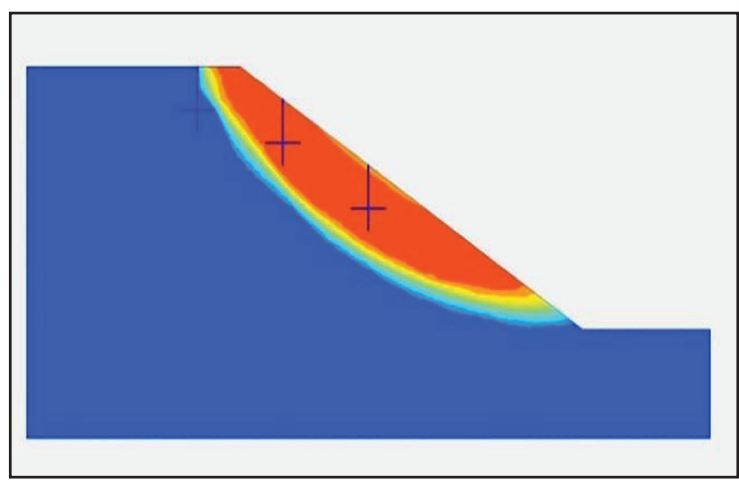

Figure 17 - Displacement Profile for a Slope $a=30^{\circ}, H=15 \mathrm{~m}\left(\varnothing 30^{\circ}-c 10\right)$, Sqr. $(D-1 / W-1)$, Shear $\mathrm{K}$ for the Foundation base

\subsubsection{Slope Augmentation with Retaining Walls Reinforced with Tieback Soil Anchors}

Table 16 produces interesting results, where FOS has gained significantly $(\approx 27 \%)$ with the slope modifications and subsequent introduction of soil anchors. However, it is noteworthy that this necessitates appropriate technology and workmanship in the design and construction of soil anchors. Soil anchoring is most effective when the slope height is above $5 \mathrm{~m}$ and for difficult locations where retaining walls cannot be employed.

Table 16 - FOS Improvement with Different Modification Approaches for a Slope $a=30^{\circ}$ with $H=15 \mathrm{~m}\left(\varnothing 30^{\circ}-c 10\right)$, Sqr. $(D-1 / W-1)$

\begin{tabular}{|l|c|c|}
\hline $\begin{array}{l}\text { Number } \\
\text { of } \\
\text { floors }\end{array}$ & $\begin{array}{c}\text { Retaining } \\
\text { walls } \\
\text { without } \\
\text { anchors }\end{array}$ & $\begin{array}{c}\text { Retaining } \\
\text { walls with } \\
\text { anchors }\end{array}$ \\
\hline Single & 1.559 & 1.981 \\
\hline Two & 1.523 & 1.940 \\
\hline Three & 1.486 & 1.896 \\
\hline
\end{tabular}




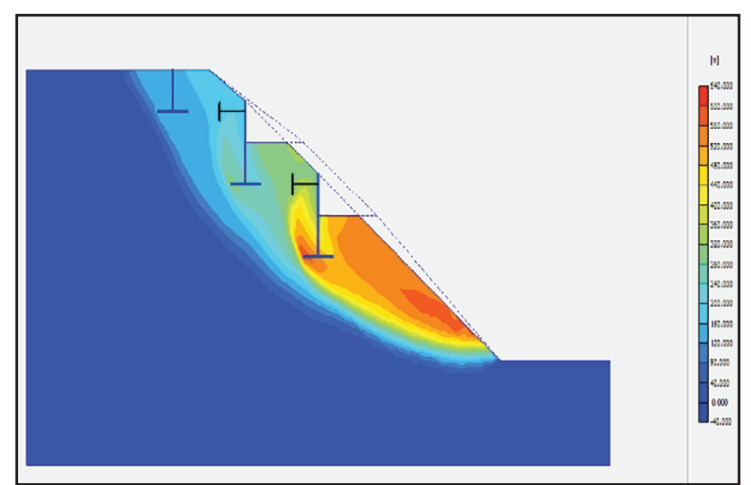

(Natural slope FOS $=1.532$ )

Figure 18 - Displacement Profile for a Slope $a=30^{\circ}, H=15 \mathrm{~m}\left(\varnothing 30^{\circ}-c 10\right)$, Sqr. $(D-1 / W-1)$, Anchor Reinforced Retaining Walls

4.6 Group of Safe Foundation Models for Low-Rise Building Structures Placed on Steep Drained Coarse-Grained Soil Slopes

Based on the findings of sections 4.3 to 4.5 , a group of safe foundation models were proposed in the format presented in Figure 19. Section 3.3 elaborates the guides to the usage of these models.

At this point, the authors would like to draw the reader's attention to the detailed Models presented in Appendix B, from Figure B1 to Figure B14, including Figure 19. Figure 19 and
Figure B1 to Figure B3 depict the requirement of adopting more simpler foundation models to complex "last resort strategies" models because the slope height increases. For slopes of $a=30^{\circ}$ and $\varnothing=30^{\circ}$ with $H=25 \mathrm{~m}$, none of the proposed model foundations suit even a single storied building. This fact gets more intensified as the slope angle increases to $a=33^{0}$. The threshold height reduces to $10 \mathrm{~m}$ for slopes of $\varnothing=30^{\circ}$ (through Figure B4 to Figure B6). Even for $10 \mathrm{~m}$ height slopes, it is necessary to seek complex "last resort strategies" for low cohesive soils.

\section{Discussion}

The achieved results for the initially mentioned research objectives are summarised as follows:

The local slopes have been categorised geometrically, based solely on the slope angle, ranging from flatlands to steep slopes.

The existing geotechnical databases and the number of laboratory direct shear tests performed for samples obtained from random sites have revealed that the soil slopes made of coarse-grained residual soils have a drained angle of internal friction $(\varnothing)$ in the range of $30^{\circ}$ $-38^{\circ}$ and the drained cohesion (c) between 1.0 $\mathrm{kPa}$ and $10.0 \mathrm{kPa}$.

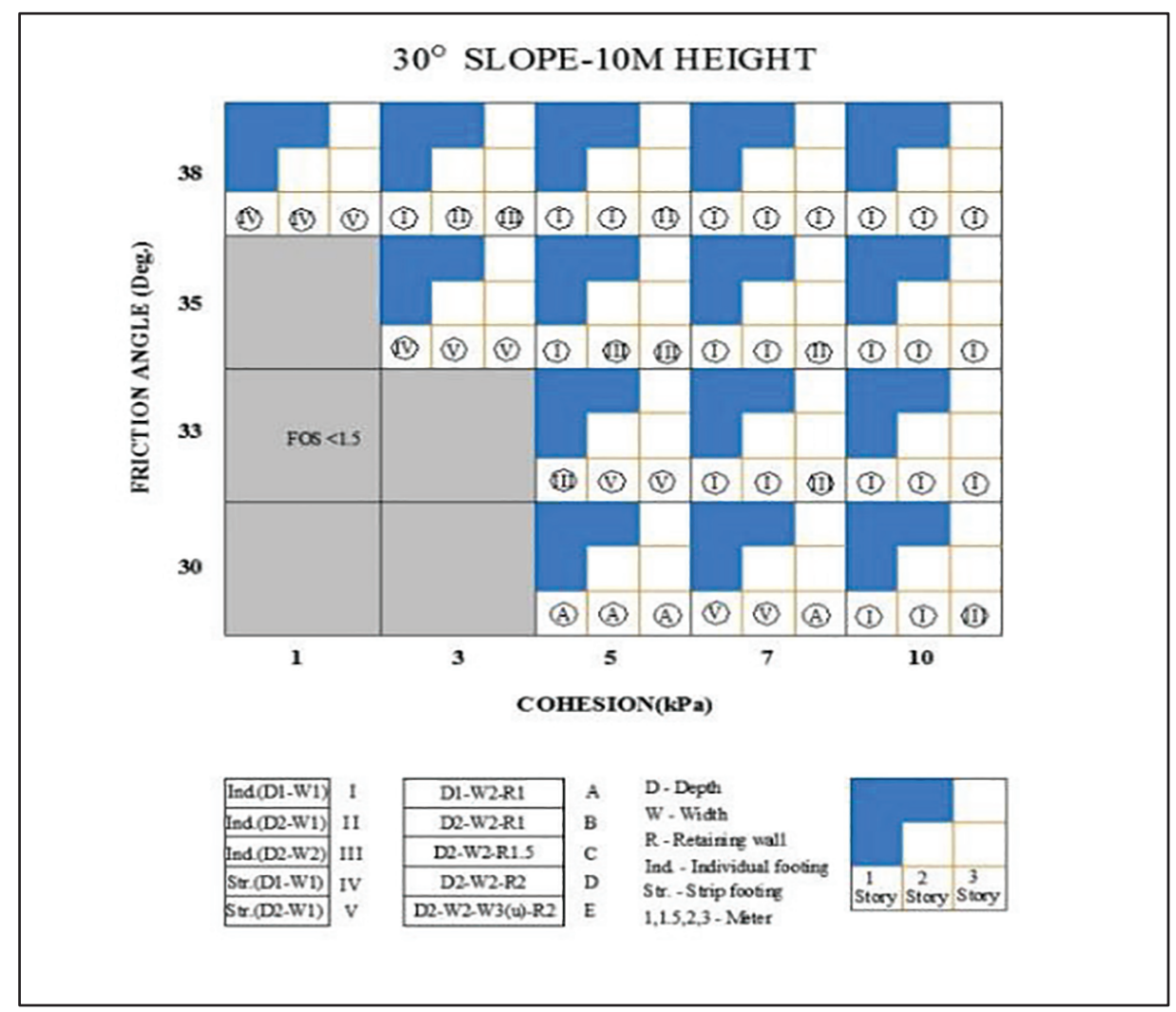

Figure 19 - Foundation Criteria Solutions for a Slope Angle of $30^{0}$ with a Height of $10 \mathrm{~m}$ 
The dry unit weight of this type of soils can be estimated to be $18 \mathrm{kN} / \mathrm{m}^{3}$. The results agree with the values published in standard literature and as reported by Das, 2010 [5].

The differences between the FOS results generated by the three different slope stability analysis techniques are found to be insignificant. During the analysis for comparison between techniques, the difference between the FOS with surcharge and without surcharge is found to be insignificant, and authors speculate that this may be due to the comparatively smaller surcharge applied to that of the weight of the natural slope.

When considering the stability of natural slopes, the sample cases discussed under section 4.3 revealed that FOS of a slope under constant shear strength condition $\left(\varnothing 30^{\circ}-c 10\right)$ decreases by $9.8 \%$ to $21.5 \%$ as the slope angle increases from $30^{\circ}$ to $37^{\circ}$ (keeping height constant). It decreases by $21.7 \%$ to $31.9 \%$ as the slope height increases from $10 \mathrm{~m}$ to $25 \mathrm{~m}$ (keeping slope angle constant), and slope becomes unstable as the slope angle approaches $40^{\circ}$. Under constant slope angle $\left(a=33^{\circ}\right)$ conditions, the reduction in FOS is around $17.5 \%$ to $20.5 \%$ as the slope height increases from $15 \mathrm{~m}$ to $35 \mathrm{~m}$ with different shear strength parameter combinations. The FOS reduction due to the shear strength reduction is about $13 \%$ to $14 \%$, for which the angle of internal friction is the main contributor. Again, slopes become unstable as the slope height reaches $40 \mathrm{~m}$.

For constant slope height $(15 \mathrm{~m})$ conditions, the FOS reduction was around $25.5 \%$ to $32.5 \%$ due to increased slope angle from $30^{\circ}$ to $40^{\circ}$ under constant shear strength conditions. In contrast, a reduction of FOS of around 0.8 to 1.2 times the reduction of $\varnothing$ and about 0.3 to 0.4 times the reduction of $c$ can be observed under constant slope angle scenarios.

In generalising the above findings, the following facts can be concluded by referring through Table 9 and Table 10 in the main text and Table A1-1 to Table A1-8 in Appendix A-1.

Under lowest-shear strength conditions, FOS has been reduced by $8.3 \%$ (shallow slopes-10$15 \mathrm{~m}$ ) to $23.1 \%$ (deeper slopes-20- $25 \mathrm{~m}$ ) when the slope angle increases from $30^{\circ}$ to $35^{\circ}$, while the reduction of FOS for the same slope geometry variation for highest-shear strength conditions is $5.7 \%$ to $14.7 \%$.
An increase of slope angle from $35^{\circ}$ to $40^{\circ}$ reduced the FOS by as much as $34.2 \%$ in lowshear strength-shallow slope conditions, which is almost half of its $(18.7 \%)$ high-shear strength-shallow slope conditions. The FOS reduction in high-shear strength-deep slope conditions is around $13 \%$ due to the increase of slope angle from $30^{\circ}$ to $35^{\circ}$.

When considering the effects of slope height variation, under constant slope angle conditions, FOS reduction of $12.4 \%$ to $14.4 \%$ is observed when the slope height increased from $10 \mathrm{~m}$ to $15 \mathrm{~m}$ for flatter slopes $\left(30^{0}-35^{\circ}\right)$ lowest-shear strength conditions, and for the same slopes the reduction percentages of FOS continuously decrease during the increase of slope height from $15 \mathrm{~m}$ to 20 . Then from $25 \mathrm{~m}$, which is found to be the critical height condition, from which onwards the slope height factor has little influence on the FOS.

For these particular cases, a critical height of $20 \mathrm{~m}$ is found to be applicable for a slope of $a=30^{\circ}$ and $\left(\varnothing 30^{\circ}-c 1\right)$ and a critical height of $20-25 \mathrm{~m}$ for a slope of $a=30^{\circ}$ and $\left(\varnothing 38^{\circ}-c 1\right)$.

FOS reduction under both slope angle and height variations were found to be non-linear, in which the initial FOS reduction gradient is much lower for flatter slope angles and higher for steeper angles.

On the other hand, it is the opposite for FOS reduction behaviour with slope height variations. Here, the initial FOS reduction gradients corresponding to shallower slope heights are comparatively higher than that of deeper slopes and (most probably) due to the approach of the critical height zone.

By considering the shear strength parameter effects under constant slope angle and slope height conditions, it can be concluded that a reduction of FOS of 0.8 (high cohesive soils) to 1.4 (low cohesive soils) times the reduction of $\varnothing$ and about 0.2 (high friction soils) to 0.4 (low friction soils) times the reduction of $c$ can be observed, irrespective of the slope angle and the slope height. Hence these parameters are found to be extremely sensitive in deciding FOS levels, while the angle of internal friction has a more significant influence.

Outcomes of the loaded slopes can be analysed through Table 12 in the main text and Table A2-1 to Table A2-8 in Appendix A-2. Accordingly, none of the slope geometries, 
foundation criteria or building loads can safely sustain under the lowest shear strength (Ø30 c 01) conditions. Conversely, $30^{\circ}$ angled slopes of heights up to $25 \mathrm{~m}$ are found to be safe with all the foundation criteria and for all three types of building loads under the highest shear strength parameter $(\varnothing 38-c 10)$ conditions. This shear strength parameter combination is found to be providing safer slopes for most of the building loads and foundation criteria, even for shallow $(10 \mathrm{~m})$ - steep $\left(40^{\circ}\right)$ slopes. It is evident that as geometry of slopes become steepest and deepest (e.g., $a=40^{\circ}$ and $H=25 \mathrm{~m}$ ), none of the shear strength parameter combinations or the foundation criteria support safe slope conditions for any of the building loads and such cases require the "last resort strategies".

A detailed analysis revealed that for similar types of foundations criteria, the FOS reduction due to an increase in building loads is insignificant for low shear strength-flatter slopes $(1.6-6.7 \%)$, while it is pronounced for steeper slopes $(20-81 \%)$ with low shear strength soils. The minimum reduction corresponds to strip foundations placed at $2.0 \mathrm{~m}$ depth, while the maximum is found to be for pad footings with $1.0 \mathrm{~m}$ width, placed at $1.0 \mathrm{~m}$ depth; the trend is common for both flatter and steeper slopes.

Interestingly, the FOS reduction due to an increase in building loads is around $75 \%$ by adopting strip foundations paced at $2.0 \mathrm{~m}$ depth instead of pad footings with $1.0 \mathrm{~m}$ width, placed at $1.0 \mathrm{~m}$ depth for low shear strength slopes. For high shear strength slopes, the aforementioned trend reduces to around $50 \%$, unlike in lower shear strength case. For high shear strength steep-deep slopes, the marked FOS reduction due to load increments was not evident and probably due to the neighbourhood of the critical height of the case considered.

When considering the direct FOS improvement effects by two foundation types, adopting strip footings over pad footings has more significant effects in flatter-low shear strength slopes; the contribution increases as loads and founding depth increase. Again, for high strength-steep shallow and deep slopes, adoption of different foundation types has contributed insignificantly to improve the FOS, most probably due to the approach of critical height effects.
The width and depth of foundations for both types of foundations have contributed insignificantly for most soil slopes, except for heavily loaded low shear strength-steep slopes. Here, the depth contributes to increasing by $28 \%$ for steep-deep slopes loaded with three-storied buildings, while by as much as around 35\% for three-storied loaded steepshallow slopes due to the increase in width of pad footings for the same low shear strength slopes.

The proposed foundation models presented in Appendix $B$ are an extension of the results in Appendix A-2, which include "last resort strategies" mentioned above. The produced models resulted from a vast repetitive and iterative process to reach the most economical type for each case. As explained in section 4.6, the capability of adopting more economical foundation criteria diminishes either because shear strength parameters get low or slope geometries become steeper and deeper.

It is noteworthy to mention that the proposed foundation models have been developed, not only based on safety but also considering the economic aspects. Hence the left side greyish areas in each model are corresponding to the scenarios only where proposed economical type solutions cannot be recommended. If one sought a foundation solution to be implemented in such scenarios, a more costly solution could be implemented to reach the required FOS levels to utilise the precious land area.

Fundamentally, the Type I category of foundations, found to be the most economical, can be implemented for all the highest soil shear strength parameter cases, except for the steepest slope $\left(40^{\circ}\right)$ condition. On the other extreme, even a minimum economic foundation type cannot be recommended for the lowest-shear strength soil slopes with the least geometric vulnerably.

\section{Conclusions and Recommendations}

\subsection{Conclusions}

The following conclusions can be made according to the findings of this study:

1. Based on the literature review, it has been identified that local slope categorisation is based on the angle of the slope, ranging from flatlands $\left(a \lesssim 5^{\circ}\right)$, gentle slopes $\left(a \approx 5^{\circ}\right.$ $\left.-11^{\circ}\right)$, moderate slopes $\left(a \approx 11^{\circ}-17^{\circ}\right)$, 
intermediate slopes $\left(a \approx 17^{\circ}-31^{\circ}\right)$, to steep slopes $\left(a \gtrsim 31^{\circ}\right)$.

2. Coarse-grained soil slopes in most parts of the central highlands of Sri Lanka are composed of residual soils with drained shear strength parameters in the range of $30^{\circ}-38^{\circ}$ for a drained angle of internal friction $(\varnothing)$ and $1.0 \mathrm{kPa}-10.0 \mathrm{kPa}$ for drained cohesion (c).

3. For natural (unloaded) slopes, the following facts can be concluded based on this study's outcomes.

> The stability of natural slopes is governed by three indivisible parameters: slope geometry (slope angle and slope height), shear strength parameters of slope compounded soil mass, and the drainage behaviour (this study focussed only on fully drained slopes).

$>$ Under low shear strength slopes, as slope angle increases from flatter to moderately steeper (from $30^{\circ}$ to $35^{0}$ ), a continuous decrease of FOS is found to be less $(8.3 \%)$ for shallow slopes when compared to deeper slopes (23.1\%). However, the reduction is more pronounced and rapid (34.2\%) for both shallow and deep slopes when the slope angle becomes steeper (from $35^{\circ}$ to $40^{\circ}$ ).

$>$ For high shear strength slopes, the reduction of FOS due to an increase of slope angle from flatter to moderately steeper (from $30^{\circ}$ to $35^{\circ}$ ) is found to be as low as $5.7 \%$ to $14.7 \%$ for shallow and deeper slopes, respectively; like low shear strength case, but to a less extent of reduction in FOS $18.7 \%$, when the slope angle increases from $35^{0}-40^{\circ}$ for both shallow and deep slopes.

$>$ Hence, the FOS reduction is non-linear under constant slope height- varying slope angle conditions, and similar behaviour can be observed during constant slope angle- varying slope height, but with an opposite trend due to the critical height approach.

$>$ Critical height is a function of the slope geometry and the shear strength parameters, and it increases as shear strength increases.

$>$ The effects of shear strength parameters, while keeping the other slope geometrical parameters constant, have revealed that the percentage reduction in FOS is in the range of $0.8 \times(\%$ reduction of $\varnothing)$ in high cohesive soils to $1.4 \times(\%$ reduction of $\emptyset)$ in low cohesive soils, and about $0.2 \times(\%$ reduction of $c$ ) in high friction soils to $0.4 \mathrm{x}$ (\% reduction of $c$ ) in low friction soils.

$>$ Hence, the FOS is highly sensitive to corresponding shear strength parameters, especially the angle of internal friction.

4. For loaded slopes, the following facts can be summarised:

$>$ Except for deepest and steepest slope conditions (here, $a=40^{\circ}$ and $H=25 \mathrm{~m}$ ), when slopes are of the highest possible shear strength parameter combinations, most slope geometries are safe under different loading and foundation criteria conditions.

$>$ For low shear strength slopes, FOS -Load increment response in flatter slopes is less compared to steeper slopes, while the same response becomes minimum when foundations are of strip footings, placed at $2.0 \mathrm{~m}$ depth and become maximum when pad footings with 1.0 width set at $1.0 \mathrm{~m}$ depth. Generally, strip foundations are safer compared to pad footings, especially when loads are high, and safety increases as founding depth increases for these types of soils with flatter slopes.

$>$ For high shear strength slopes, adoption of strip footings placed at $2.0 \mathrm{~m}$ depth has found to be affected to a lesser extent, while the marked FOS - Load increment response effect diminishes as slopes become steeper and deeper. Moreover, unlike in low-shear-flatter slope cases, the FOS improvement effects are insignificant with the adoption of different foundation types in high-shear-steep slopes cases.

$>$ Width and depth factors of the same foundation types are negligible for most slopes, except low shear strength-steep slopes.

5. When finding solutions where conventional foundations are either not safe or uneconomical, introducing a shear key for the foundations creates negligible effects to the FOS; contrarily, soil anchors create a significant impact to increase (by $30-40 \%$ ) the FOS.

\subsection{Recommendations}

This study was performed for residual soils under drained conditions, and hence survey outcomes are strictly valid only for the coarse- 
grained residual soils under drained conditions.

It should be emphasised that the proposed foundation models are a set of solutions in which both safety and the economic aspects are addressed. Therefore, designers are advised to seek other foundation solutions for scenarios where model solutions have not been proposed or when the building loads exceed.

This study identified the stability of both natural and loaded slopes are heavily dependent on their compounding soil shear strength parameters, and hence, it is imperative to carry out appropriate in-situ and/or laboratory tests under drain conditions to obtain the reliable shear strength parameters of soil in the site, before adopting these results.

Realistically, it is rare to find residual soils with $100 \%$ drained condition. Hence, it is essential to keep weep holes of appropriate diameters and at adequate intervals to simulate the conditions in retaining walls. Moreover, the column footings and retaining wall bases should not be cast monolithically.

As has been revealed to some extent, the critical depth factor plays a leading role in the slope stability problems, and it is essential to conduct more studies on the behaviour of critical height concept for local slope scenarios.

\section{References}

1. Hazard Resilient Housing Construction Manual, Resilient Construction Series No. 1, NBRO, Sri Lanka, 2015, pp 75-96.

2. Mounia, H. B., Farid, B., \& Messoud, S., "Investigation of Building Loads Effect on the Stability of Slope", Int. J. Civ. Environ. Eng., Vol.11, No:2, 2017, pp 140-144.
3. Kourkoulis, R., Anastasopoulos, I., Gelagoti, F., \& Gazetas, G., "Interaction of Foundation-Structure Systems with Seismically Precarious Slopes: Numerical Analysis with Strain-Softening Constitutive Model" Soil Dynamics and Earthquake Engineering, Vol. 30, No. 12, 2010, pp 1430-1445.

4. Kulathilaka, S. A. S., \& Sujeevan, V., "Rainfall Infiltration Analysis in Unsaturated Residual Soil Slopes", J. Sri Lankan Geotechnical Society, Dec. 2011.

5. Das, B. M., "Principles of Geotechnical Engineering", Seventh Edition, Henderson, Nevada, 2010.

6. Chen, H., \& Liu, S. H., "Slope Failure Characteristics and Stabilization Methods", Can. Geotech. J., April 2007, pp 377-391.

7. Sazzad, M. M., \& Haque, M. F., "Effect of Surcharge on The Stability of Slope in a Homogeneous Soil by FEM", Sec.Int. Conf, Adv. Civ. Eng., Dec 2014, pp 314-318.

8. Rabie, M., “Comparison Study between Traditional and Finite Element Methods for Slopes under Heavy Rainfall", J.Housing and Building National Research Centre, Vol.10, No.2, August 2014, pp 160168.

9. Baba, K., Bahi, L., Ouadif, L., \& Akhssas, A., "Slope Stability Evaluations by Limit Equilibrium and Finite Element Methods Applied to a Railway in the Moroccan Rif", Open J. Civ. Eng., Vol.2, March 2012, pp 2732. 
Appendix A- Detailed Results of Slope Stability Analysis

Appendix A-1 FOS variation for selected slope geometries for different drained shear strength parameter combinations under natural conditions

Table A1-1: For a slope of $a=30^{\circ}$ and $H=10 \mathrm{~m}$

\begin{tabular}{|c|c|c|c|c|}
\hline \multirow{2}{*}{$\begin{array}{c}\text { Cohesion } \\
\text { (kPa) }\end{array}$} & \multicolumn{4}{|c|}{ Friction Angle $\left(\varnothing^{0}\right)$} \\
\hline & $\varnothing-30$ & $\varnothing-33$ & $\varnothing-35$ & $\varnothing-38$ \\
\hline 1 & 1.21 & 1.34 & 1.45 & 1.60 \\
\hline 3 & 1.37 & 1.50 & 1.64 & 1.79 \\
\hline 5 & 1.54 & 1.68 & 1.77 & 1.94 \\
\hline 7 & 1.66 & 1.83 & 1.93 & 2.10 \\
\hline 10 & 1.84 & 2.09 & 2.10 & 2.29 \\
\hline
\end{tabular}

Table A1-3: For a slope of $a=30^{\circ}$ and $H=25 \mathrm{~m}$

\begin{tabular}{|c|c|c|c|c|}
\hline & \multicolumn{4}{|c|}{ Friction Angle $\left(\varnothing^{0}\right)$} \\
\hline (kPa) & $\varnothing-30$ & $\varnothing-33$ & Ø-35 & $\varnothing-38$ \\
\hline 1 & 1.04 & 1.21 & 1.31 & 1.42 \\
\hline 3 & 1.18 & 1.30 & 1.38 & 1.54 \\
\hline 5 & 1.25 & 1.38 & 1.48 & 1.62 \\
\hline 7 & 1.31 & 1.44 & 1.54 & 1.69 \\
\hline 10 & 1.40 & 1.53 & 1.63 & 1.78 \\
\hline
\end{tabular}

Table A1-5: For a slope of $a=35^{\circ}$ and $H=15 \mathrm{~m}$

\begin{tabular}{|c|c|c|c|c|}
\hline \multirow{2}{*}{$\begin{array}{c}\text { Cohesion } \\
\text { (kPa) }\end{array}$} & \multicolumn{4}{|c|}{ Friction Angle $\left(\varnothing^{0}\right)$} \\
\hline & $\varnothing-30$ & $\varnothing-33$ & $\varnothing-35$ & $\varnothing-38$ \\
\hline 1 & 0.95 & 1.12 & 1.22 & 1.32 \\
\hline 3 & 1.11 & 1.24 & 1.30 & 1.51 \\
\hline 5 & 1.25 & 1.35 & 1.43 & 1.56 \\
\hline 7 & 1.32 & 1.54 & 1.61 & 1.75 \\
\hline 10 & 1.54 & 1.66 & 1.72 & 1.86 \\
\hline
\end{tabular}

Table A1-7: For a slope of $a=35^{\circ}$ and $H=25 \mathrm{~m}$

\begin{tabular}{|c|c|c|c|c|}
\hline \multirow{2}{*}{$\begin{array}{c}\text { Cohesion } \\
(\mathbf{k P a})\end{array}$} & \multicolumn{4}{|c|}{ Friction Angle $\left(\varnothing^{0}\right)$} \\
\hline & $\varnothing-30$ & $\varnothing-33$ & $\varnothing-35$ & $\varnothing-38$ \\
\hline 1 & 0.80 & 0.93 & 1.01 & 1.12 \\
\hline 3 & 1.00 & 1.10 & 1.15 & 1.23 \\
\hline 5 & 1.07 & 1.18 & 1.26 & 1.39 \\
\hline 7 & 1.13 & 1.25 & 1.30 & 1.46 \\
\hline 10 & 1.12 & 1.34 & 1.42 & 1.55 \\
\hline
\end{tabular}

Table A1-2: For a slope of $a=30^{\circ}$ and $H=20 \mathrm{~m}$

\begin{tabular}{|c|c|c|c|c|}
\hline Cohesion & \multicolumn{4}{|c|}{ Friction Angle $\left(\varnothing^{0}\right)$} \\
\hline (kPa) & $\varnothing-30$ & $\varnothing-33$ & $\varnothing-35$ & $\varnothing-38$ \\
\hline 1 & 1.04 & 1.22 & 1.32 & 1.42 \\
\hline 3 & 1.23 & 1.37 & 1.46 & 1.55 \\
\hline 5 & 1.31 & 1.45 & 1.52 & 1.69 \\
\hline 7 & 1.40 & 1.54 & 1.64 & 1.79 \\
\hline 10 & 1.51 & 1.64 & 1.75 & 1.91 \\
\hline
\end{tabular}

Table A1-4: For a slope of $a=35^{\circ}$ and $H=10 \mathrm{~m}$

\begin{tabular}{|c|c|c|c|c|}
\hline \multirow{2}{*}{$\begin{array}{c}\text { Cohesion } \\
\text { (kPa) }\end{array}$} & \multicolumn{4}{|c|}{ Friction Angle $\left(\varnothing^{0}\right)$} \\
\hline & $\varnothing-30$ & $\varnothing-33$ & $\varnothing-35$ & $\varnothing-38$ \\
\hline 1 & 1.11 & 1.24 & 1.33 & 1.47 \\
\hline 3 & 1.27 & 1.41 & 1.50 & 1.63 \\
\hline 5 & 1.42 & 1.56 & 1.64 & 1.82 \\
\hline 7 & 1.55 & 1.70 & 1.81 & 1.96 \\
\hline 10 & 1.72 & 1.86 & 1.96 & 2.16 \\
\hline
\end{tabular}

Table A1-6: For a slope of $a=35^{\circ}$ and $H=20 \mathrm{~m}$

\begin{tabular}{|c|r|r|r|r|}
\hline \multirow{2}{*}{$\begin{array}{c}\text { Cohesion } \\
(\mathbf{k P a})\end{array}$} & \multicolumn{4}{|c|}{ Friction Angle $\left(\boldsymbol{\emptyset}^{\mathbf{0}}\right)$} \\
\hline & $\boldsymbol{\varnothing - 3 0}$ & $\boldsymbol{\varnothing - 3 3}$ & \multicolumn{1}{|c|}{$\boldsymbol{\varnothing - 3 5}$} & \multicolumn{1}{|c|}{$\boldsymbol{\varnothing - 3 8}$} \\
\hline 1 & 0.85 & 1.03 & 1.11 & 1.21 \\
\hline 3 & 1.06 & 1.15 & 1.23 & 1.37 \\
\hline 5 & 1.13 & 1.25 & 1.33 & 1.47 \\
\hline 7 & 1.19 & 1.31 & 1.40 & 1.53 \\
\hline 10 & 1.29 & 1.41 & 1.50 & 1.63 \\
\hline
\end{tabular}

Table A1-7: For a slope of $a=40^{\circ}$ and $H=10 \mathrm{~m}$

\begin{tabular}{|c|c|c|c|c|}
\hline \multirow{2}{*}{$\begin{array}{c}\text { Cohesion } \\
\text { (kPa) }\end{array}$} & \multicolumn{4}{|c|}{ Friction Angle $\left(\varnothing^{0}\right)$} \\
\hline & $\varnothing-30$ & $\varnothing-33$ & $\varnothing-35$ & $\varnothing-38$ \\
\hline 1 & 0.73 & 1.06 & 1.14 & 1.26 \\
\hline 3 & 1.12 & 1.24 & 1.39 & 1.45 \\
\hline 5 & 1.27 & 1.39 & 1.48 & 1.61 \\
\hline 7 & 1.37 & 1.50 & 1.59 & 1.73 \\
\hline 10 & 1.53 & 1.65 & 1.74 & 1.88 \\
\hline
\end{tabular}


Appendix A-2 FOS variation for selected slope geometries and with selected drained shear strength parameter combinations under different load and foundation criteria

Table A2-1: For a slope of $a=30^{\circ}$ and $H=10 \mathrm{~m}$ with (Ø30 - c01)

\begin{tabular}{|l|l|l|l|}
\hline \multirow{2}{*}{$\begin{array}{l}\text { Foundation } \\
\text { Type }\end{array}$} & \multicolumn{3}{|c|}{ Number of floors } \\
\cline { 2 - 4 } Single & Two & Three \\
\hline Sqr. $(D-1 / W-1)^{*}$ & 1.05 & 1.03 & 0.98 \\
\hline Sqr. $(D-2 / W-1)$ & 1.07 & 1.04 & 1.00 \\
\hline Sqr. $(D-2 / W-2)$ & 1.11 & 1.09 & 1.07 \\
\hline Strip $(D-1)^{* *}$ & 1.16 & 1.13 & 1.11 \\
\hline Strip $(D-2)$ & 1.23 & 1.22 & 1.21 \\
\hline
\end{tabular}

Table A2-3: For a slope of $a=40^{\circ}$ and $H=10 \mathrm{~m}$ with $(\varnothing 30-c 01)$

\begin{tabular}{l|l|l|l|}
\hline \multirow{2}{*}{$\begin{array}{l}\text { Foundation } \\
\text { Type }\end{array}$} & \multicolumn{3}{|c|}{ Number of floors } \\
\cline { 2 - 4 } & Single & Two & Three \\
\hline Sqr. $(D-1 / W-1)^{*}$ & 0.32 & 0.14 & 0.12 \\
\hline Sqr. $(D-2 / W-1)$ & 0.34 & 0.17 & 0.14 \\
\hline Sqr. $(D-2 / W-2)$ & 0.36 & 0.29 & 0.19 \\
\hline Strip $(D-1)^{* *}$ & 0.38 & 0.32 & 0.22 \\
\hline Strip $(D-2)$ & 0.40 & 0.36 & 0.32 \\
\hline
\end{tabular}

Table A2-5: For a slope of $a=30^{\circ}$ and $H=10 \mathrm{~m}$ with $(\varnothing 38-c 10)$

\begin{tabular}{|l|lll|}
\hline \multirow{2}{*}{$\begin{array}{l}\text { Foundation } \\
\text { Type }\end{array}$} & \multicolumn{3}{|c|}{ Number of floors } \\
\cline { 2 - 4 } & Single & Two & Three \\
\hline Sqr. $(D-1 / W-1)^{*}$ & 2.04 & 1.90 & 1.74 \\
\hline Sqr. $(D-2 / W-1)$ & 2.10 & 1.92 & 1.82 \\
\hline Sqr. $(D-2 / W-2)$ & 2.14 & 1.97 & 1.90 \\
\hline Strip $(D-1) * *$ & 2.16 & 1.98 & 1.91 \\
\hline Strip $(D-2)$ & 2.20 & 2.09 & 2.03 \\
\hline
\end{tabular}

Table A2-7: For a slope of $a=40^{\circ}$ and $H=10 \mathrm{~m}$ with $(\varnothing 38-c 10)$

\begin{tabular}{|l|l|l|l|}
\hline \multirow{2}{*}{$\begin{array}{l}\text { Foundation } \\
\text { Type }\end{array}$} & \multicolumn{3}{|c|}{ Number of floors } \\
\cline { 2 - 4 } & Single & Two & Three \\
\hline Sqr. $(D-1 / W-1)^{*}$ & 1.57 & 1.45 & 1.31 \\
\hline Sqr. $(D-2 / W-1)$ & 1.59 & 1.49 & 1.42 \\
\hline Sqr. $(D-2 / W-2)$ & 1.61 & 1.51 & 1.46 \\
\hline Strip $(D-1)^{* *}$ & 1.63 & 1.54 & 1.49 \\
\hline Strip $(D-2)$ & 1.65 & 1.57 & 1.53 \\
\hline
\end{tabular}

Table A2-2: For a slope of $a=30^{\circ}$ and $H=25 \mathrm{~m}$ with $(\varnothing 30-c 01)$

\begin{tabular}{|l|l|l|l|}
\hline \multirow{2}{*}{$\begin{array}{l}\text { Foundation } \\
\text { Type }\end{array}$} & \multicolumn{3}{|c|}{ Number of floors } \\
\cline { 2 - 4 } & Single & Two & Three \\
\hline Sqr. $(D-1 / W-1)^{*}$ & 1.02 & 1.01 & 0.96 \\
\hline Sqr. $(D-2 / W-1)$ & 1.03 & 1.01 & 0.99 \\
\hline Sqr. $(D-2 / W-2)$ & 1.04 & 1.02 & 1.01 \\
\hline Strip $(D-1) * *$ & 1.05 & 1.04 & 1.03 \\
\hline Strip $(D-2)$ & 1.06 & 1.04 & 1.03 \\
\hline
\end{tabular}

Table A2-4: For a slope of $a=40^{\circ}$ and $H=25 \mathrm{~m}$ with $(\varnothing 30-c 01)$

\begin{tabular}{|l|l|l|l|}
\hline \multirow{2}{*}{$\begin{array}{l}\text { Foundation } \\
\text { Type }\end{array}$} & \multicolumn{3}{|c|}{ Number of floors } \\
\cline { 2 - 4 } & Single & Two & Three \\
\hline Sqr. $(D-1 / W-1)^{*}$ & 0.37 & 0.15 & 0.07 \\
\hline Sqr. $(D-2 / W-1)$ & 0.40 & 0.19 & 0.09 \\
\hline Sqr. $(D-2 / W-2)$ & 0.42 & 0.21 & 0.12 \\
\hline Strip $(D-1) * *$ & 0.44 & 0.24 & 0.14 \\
\hline Strip $(D-2)$ & 0.47 & 0.27 & 0.17 \\
\hline
\end{tabular}

Table A2-6: For a slope of $a=30^{\circ}$ and $H=25 \mathrm{~m}$ with $(\varnothing 38-c 10)$

\begin{tabular}{|l|l|l|l|}
\hline \multirow{2}{*}{$\begin{array}{l}\text { Foundation } \\
\text { Type }\end{array}$} & \multicolumn{3}{|c|}{ Number of floors } \\
\cline { 2 - 4 } & Single & Two & Three \\
\hline Sqr. $(D-1 / W-1)^{*}$ & 1.71 & 1.68 & 1.66 \\
\hline Sqr. $(D-2 / W-1)$ & 1.73 & 1.70 & 1.68 \\
\hline Sqr. $(D-2 / W-2)$ & 1.75 & 1.72 & 1.70 \\
\hline Strip $(D-1) * *$ & 1.78 & 1.75 & 1.73 \\
\hline Strip $(D-2)$ & 1.80 & 1.77 & 1.75 \\
\hline
\end{tabular}

Table A2-8: For a slope of $a=40^{\circ}$ and $H=25 \mathrm{~m}$ with $(\varnothing 38-c 10)$

\begin{tabular}{|l|l|l|l|}
\hline \multirow{2}{*}{$\begin{array}{l}\text { Foundation } \\
\text { Type }\end{array}$} & \multicolumn{3}{|c|}{ Number of floors } \\
\cline { 2 - 4 } & Single & Two & Single \\
\hline Sqr. $(D-1 / W-1)^{*}$ & 1.22 & 1.17 & 1.15 \\
\hline Sqr. $(D-2 / W-1)$ & 1.25 & 1.20 & 1.18 \\
\hline Sqr. $(D-2 / W-2)$ & 1.27 & 1.23 & 1.22 \\
\hline Strip $(D-1)^{* *}$ & 1.29 & 1.26 & 1.24 \\
\hline Strip $(D-2)$ & 1.31 & 1.29 & 1.27 \\
\hline
\end{tabular}


Appendix B - Foundation criteria solutions for slopes with different slope geometries and drained shear strength parameters

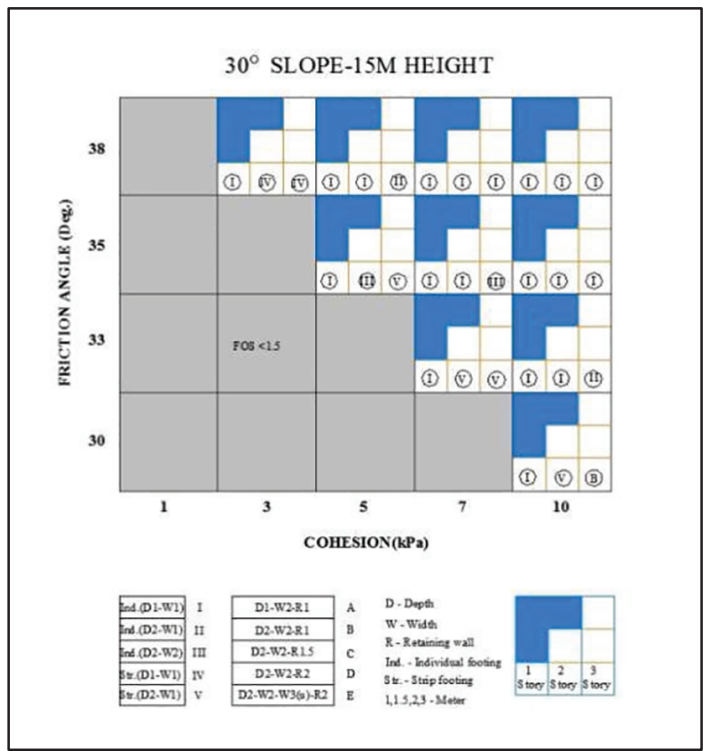

Figure B1 - For a slope angle of $30^{\circ}$ with a height of $15 \mathrm{~m}$

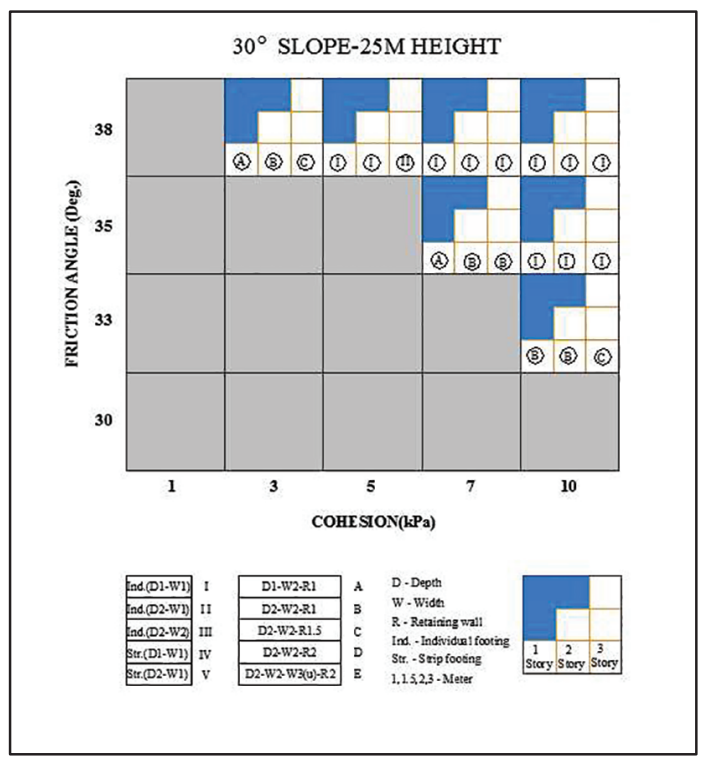

Figure B3 - For a slope angle of $30^{0}$ with a height of $25 \mathrm{~m}$

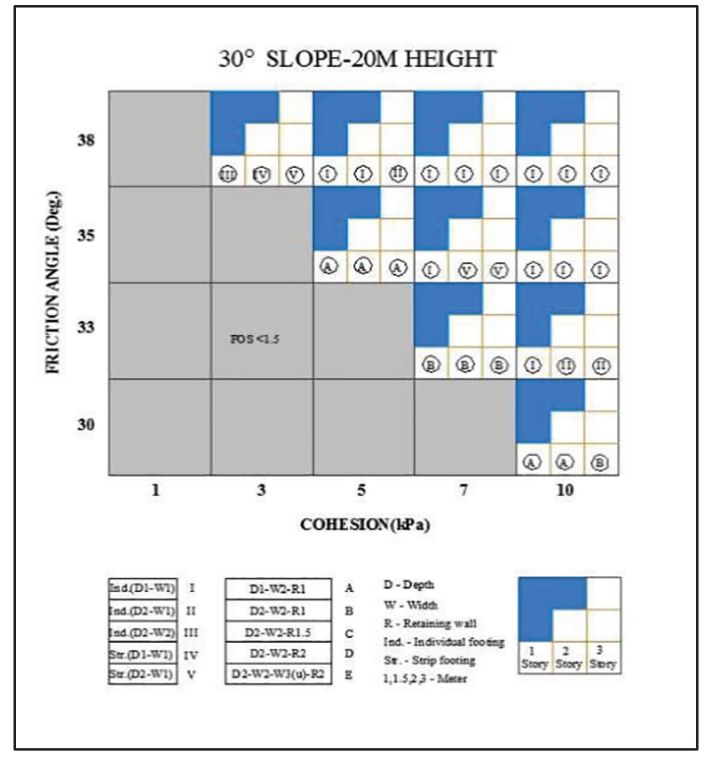

Figure B2 - For a slope angle of $30^{\circ}$ with a height of $20 \mathrm{~m}$

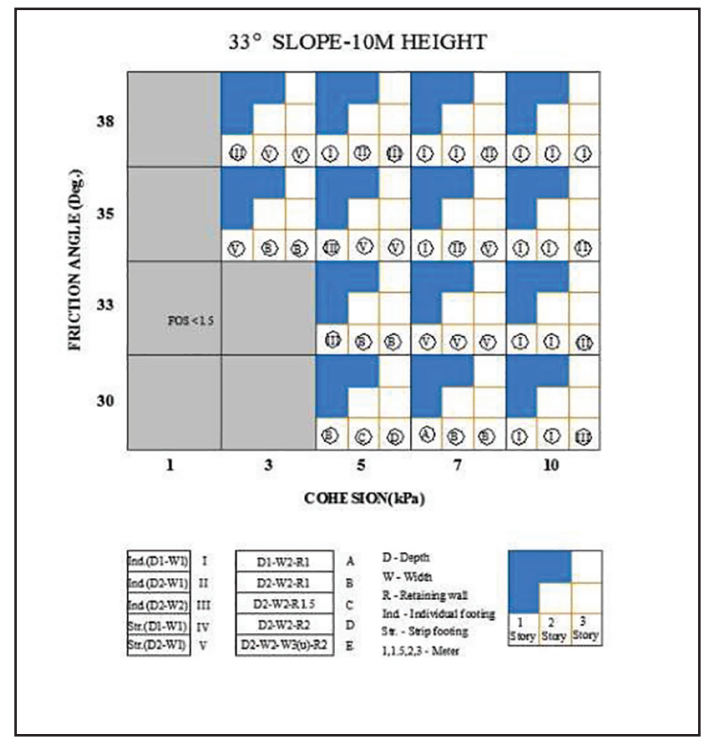

Figure B4 - For a slope angle of $33^{0}$ with a height of $10 \mathrm{~m}$ 


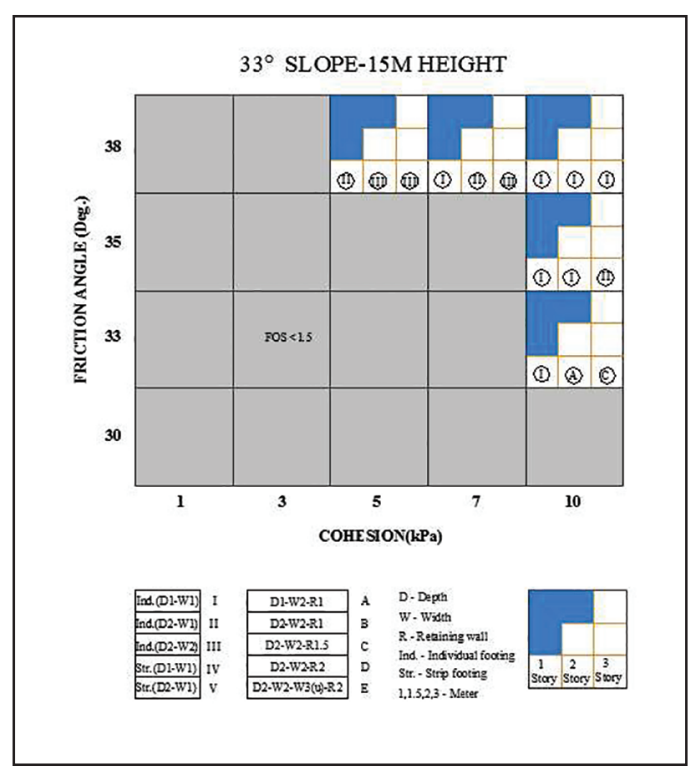

Figure B5 - For a slope angle of $33^{0}$ with a height of $15 \mathrm{~m}$

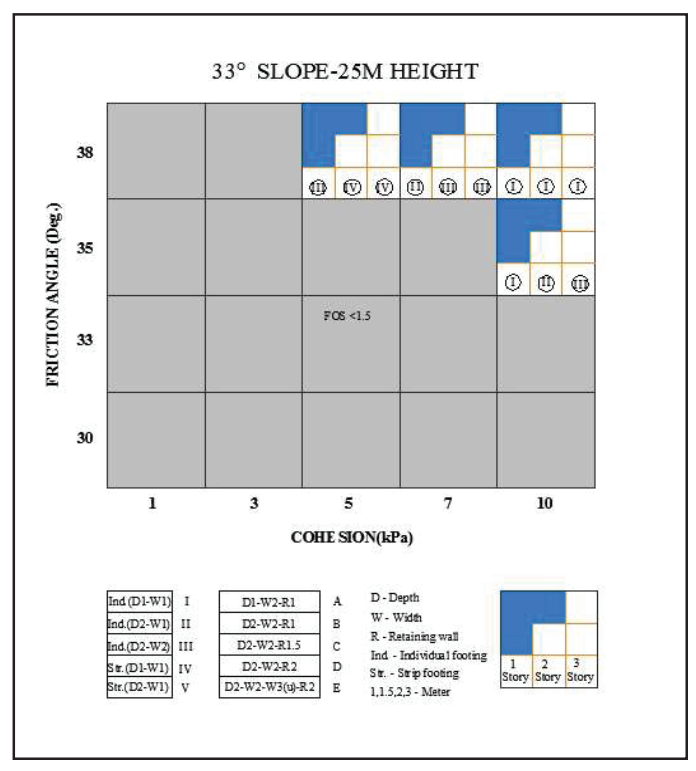

Figure B7 - For a slope angle of $33^{0}$ with a height of $25 \mathrm{~m}$

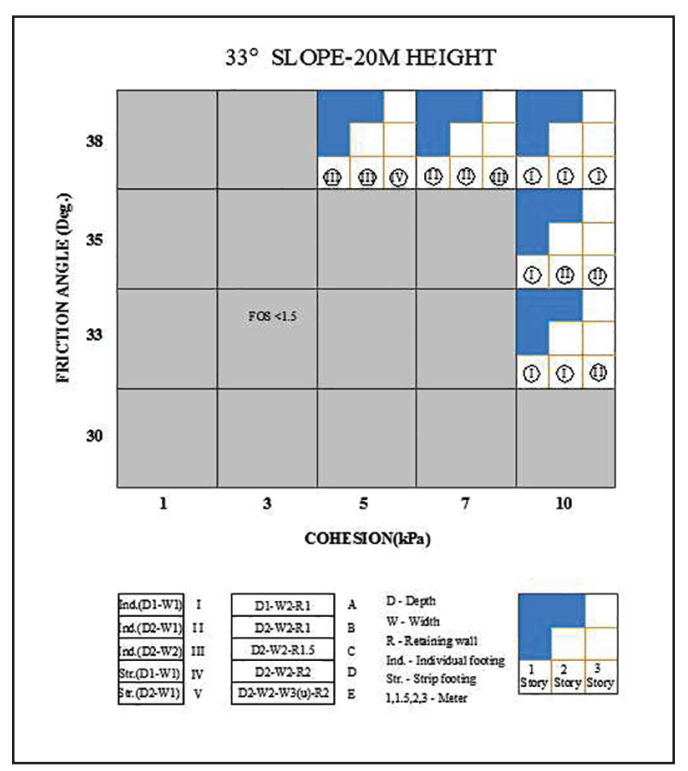

Figure B6 - For a slope angle of $33^{0}$ with a height of $20 \mathrm{~m}$

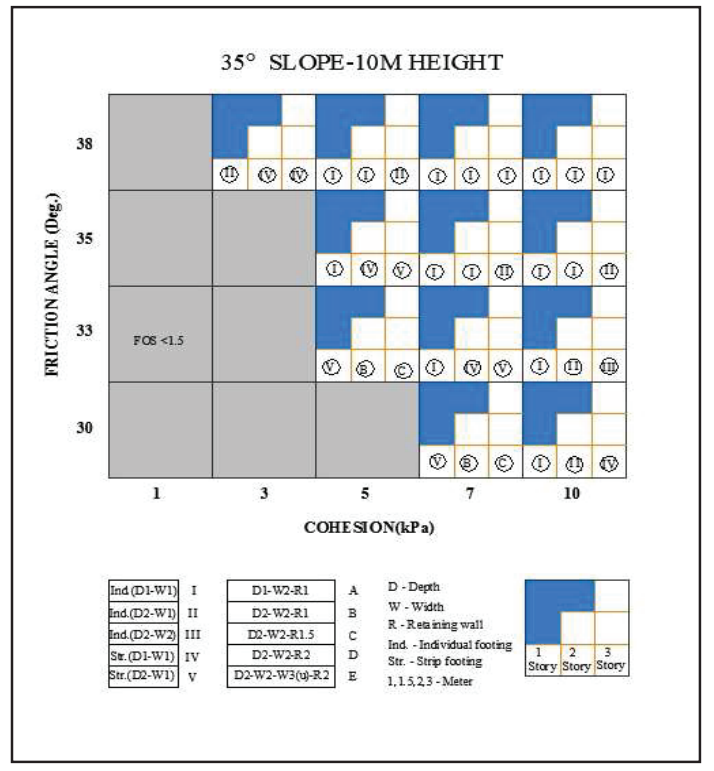

Figure B8 - For a slope angle of $35^{0}$ with a height of $10 \mathrm{~m}$ 


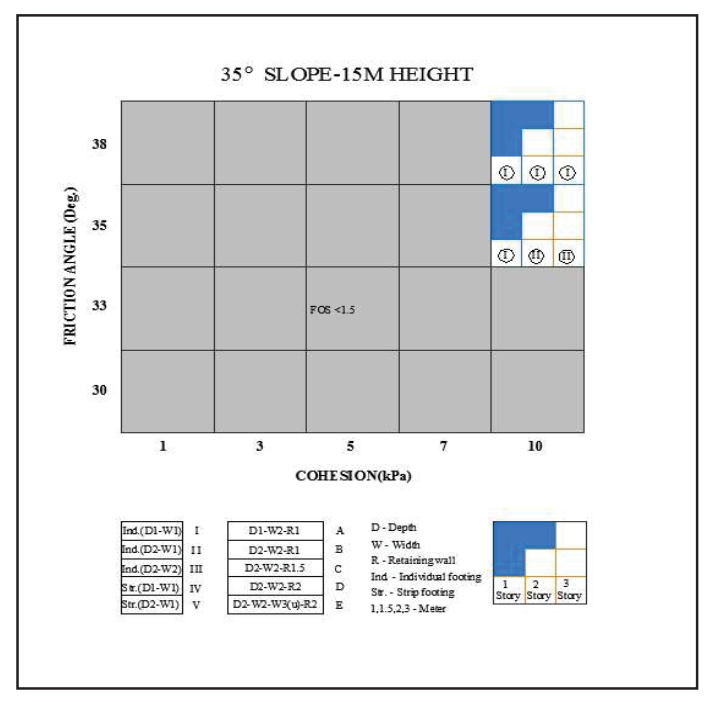

Figure B9 - For a slope angle of $35^{0}$ with a height of $15 \mathrm{~m}$

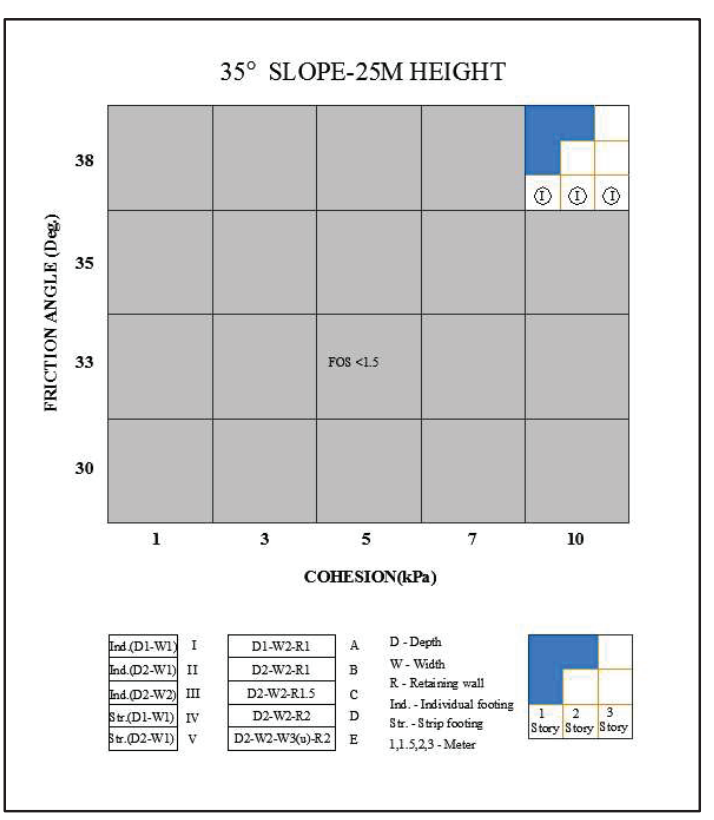

Figure B11 - For a slope angle of $35^{0}$ with a height of $25 \mathrm{~m}$

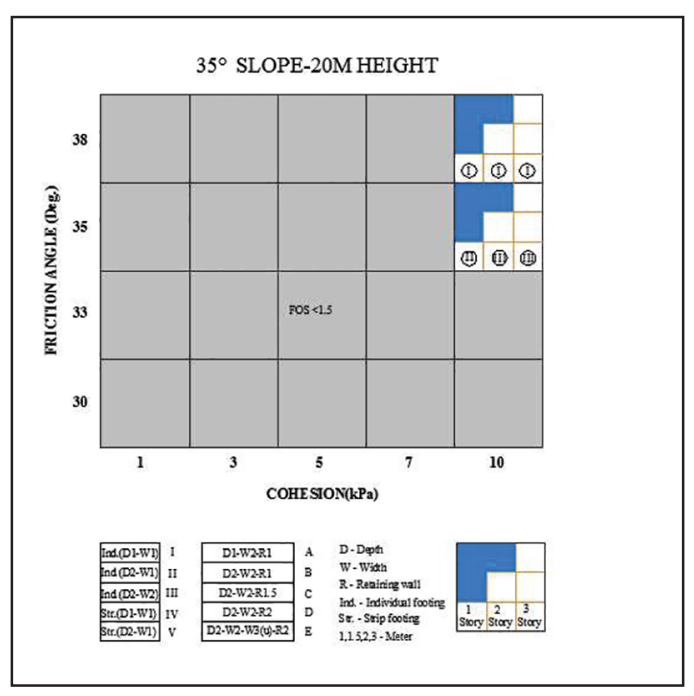

Figure B10 - For a slope angle of $35^{0}$ with a height of $20 \mathrm{~m}$

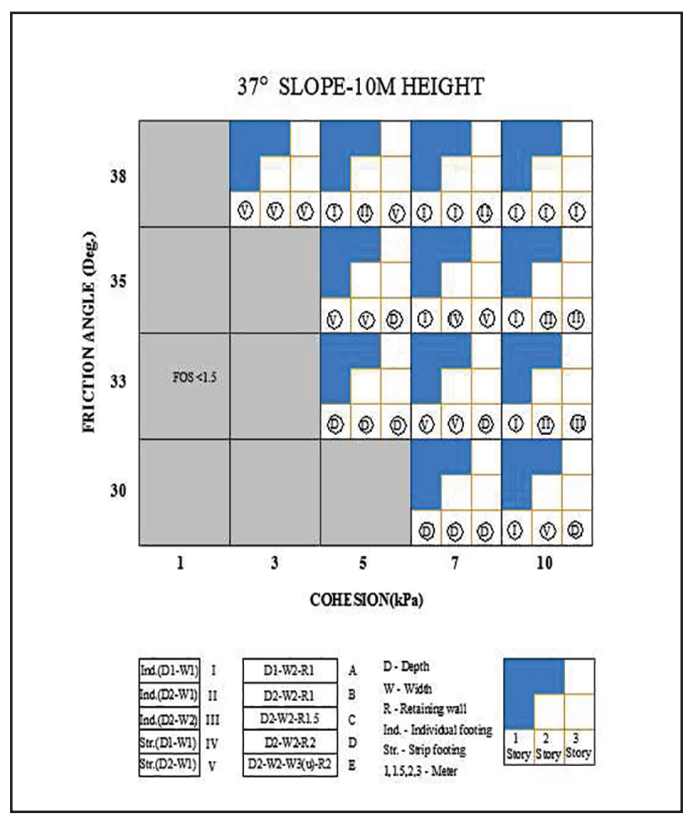

Figure B12 - For a slope angle of $37^{0}$ with a height of $10 \mathrm{~m}$ 


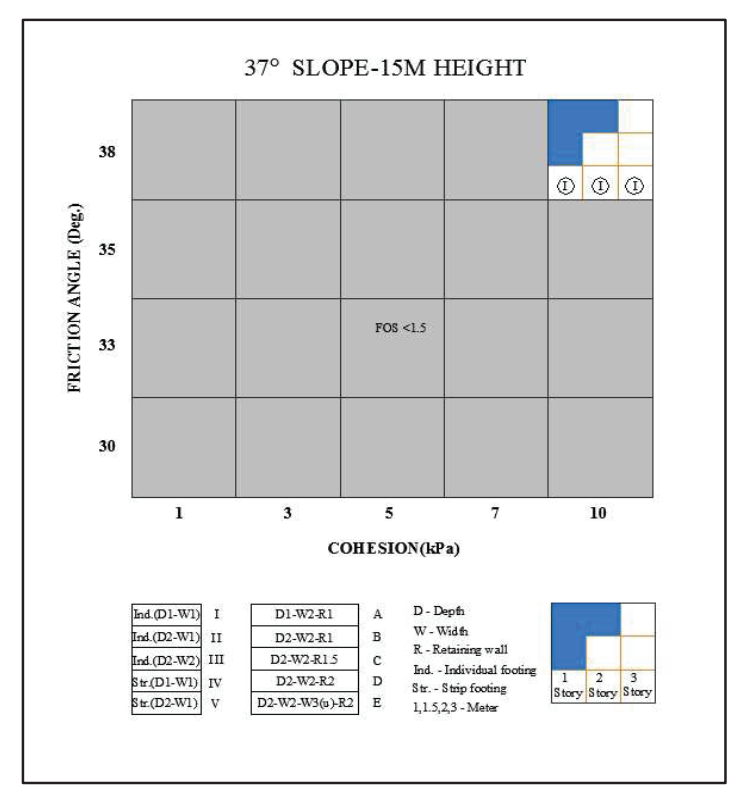

Figure B13 - For a slope angle of $37^{0}$ with a height of $15 \mathrm{~m}$

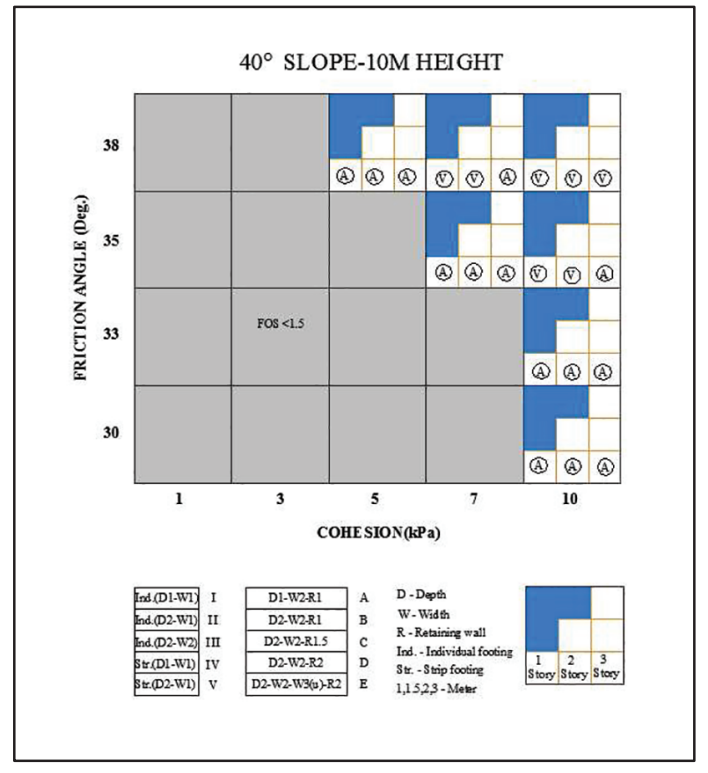

Figure B14 - For a slope angle of $40^{\circ}$ with a height of $10 \mathrm{~m}$ 